\title{
BIO-DEMOGRAPHIC AND HEALTH ASPECTS OF AGEING IN THE EU
}

\author{
JOSÉ A. HERCE \\ NAMKEE AHN \\ RICARD GÉNOVA \\ JOAQUIN PEREIRA
}

\section{CESIFO WORKING PAPER NO. 1027 \\ CATEGORY 3: SOCIAL PROTECTION \\ SEPTEMBER 2003}

Presented at CESifo Conference on Health and Economic Policy, June 2003

\footnotetext{
An electronic version of the paper may be downloaded

- from the SSRN website: Www.SSRN.com

- from the CESifo website: www.CESifo.de
} 


\title{
Bio-DEMOGRAPHIC AND HEALTH ASPECTS OF AGEING IN THE EU
}

\begin{abstract}
In this paper we describe and analyse a demographic data base that has been gathered for several EU countries under a research project called AGIR. The project tries to establish facts and evidence on the ageing process in EU countries and relate this process with health and retirement issues. Five dimensions of the ageing process have been considered: population, mortality, longevity, lifecourses and morbidity. Conventionally measured ageing can be caused by low fertility and longer lives and EU countries have experienced both. We emphasise the considerable compression of mortality that has taken place and conclude that there are still ample margin for this development to continue. Beyond age groups ratios we show that ages at major individual lifetime landmarks have been evolving in a way that may not be mutually compatible. As for how health status interacts with ageing, we do not see a clear picture emerging out of the little data available, although a simple exercise controlling by education of different cohorts tells us that European populations would probably grow healthier as they grow older.
\end{abstract}

JEL Code: I12, J10.

Keywords: ageing, health, health expectancy, European Union.

José A. Herce
FEDEA
Jorge Juan, 46
28001 Madrid
Spain
herce@fedea.es
Ricard Génova
Instituto de Salud Carlos III
c/ Sinesio Delgado, $n^{\circ} 6$ (Pabellón $\left.N^{\circ} 4\right)$.
28029- Madrid
Spain

This paper is a summary of a wider report prepared by the authors on the basis of data submitted by participating Institutes at the AGIR project developed by ENEPRI (www.enepri.org) The authors wish to thank all AGIR (Work Package 1) teams' members and also Terkel Christiansen for providing the data upon which this comparative analysis is based as well as for their comments at workshops. Also thanks are due to Jorgen Mortensen and Regina Sauto at CEPS and Jean-Marie Robine for their help and encouragement and to Rossitsa Rangelova who discussed the paper at the CESifo conference on "Health and Economic Policy" held the 24th27th of June at München. Comments from participants at that conference are also gratefully acknowledged. Thanks are also due to the European Commission for financial support under the V Framework Programme. Only the authors are responsible for any remaining shortcomings.
Namkee Ahn

FEDEA

Jorge Juan, 46

28001 Madrid

Spain

Joaquín Pereira

Instituto de Salud Carlos III

c/ Sinesio Delgado, $n^{\circ} 6$ (Pabellón $\left.N^{\circ} 4\right)$.

28029 - Madrid
Spain 


\section{Contents}

1. Introduction 3

2. Demographic trends since 1950

2.1. Population 5

2.2. Births and fertility 9

2.3. Mortality 13

2.4. Longevity 18

3. Lifecourses 25

4. Morbidity 28

4.1. Data $\quad 28$

4.2. General Health Status $\quad 30$

4.3. Disability Status 32

4.4. Health and education in the EU 34

5. Health adjusted life expectancies. Trends and future scenarios. 38

5.1. Concept and illustrations 38

5.2. Data 42

5.3. Trends in Health Expectancies 1994-1998 43

5.4. How HE relates to LE? 47

5.5. Conventional scenarios for Health Adjusted Life Expectancy 50

5.6. Education: The key to better future health status of population 54

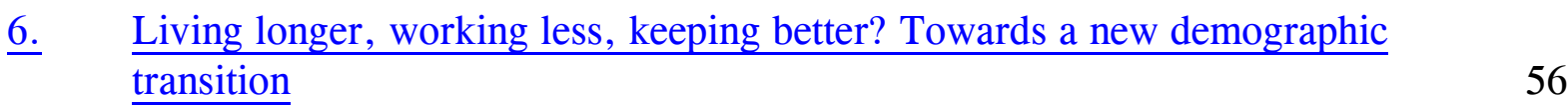

$\begin{array}{ll}\text { References } & 58\end{array}$ 


\section{Introduction}

This paper contains a summary of a wider report prepared by the authors as part of the AGIR project. National teams participating in a first phase of the project gathered comprehensive data on population, mortality, longevity, lifecourses and morbidity (health and disability) for a number of EU countries so that we were able to summarise and elaborate on these data in various directions. Data would come mostly from national sources and from the European Community Household Panel, but for completeness we have also used data from "The Human Mortality Database" (www.mortality.org). ${ }^{1}$ Countries covered are Belgium, Denmark, Germany, Spain, Finland, France, Ireland, Italy, Sweden and the United Kingdom.

The various directions we have followed to illustrate the European ageing process are:

(i) population, that is, the longest possible time series of historical and projected (2050) total population (at $31^{\text {st }}$ December) data by year gender and age (0 to 100 and/or more) to which annual number of births by gender has been added, (ii) mortality or deaths for the same years as before, by gender, year of birth and age, as well as complete life-tables by gender and both genres (survivors) for as many years (historical and projected) as possible, (iii) longevity for the same years as before (projections when needed) represented through a series of longevity indicators by gender and both genres, (iv) lifecourses, that is, major passage events in the lifecycle, or rather the ages at which these happen, concerning schooling, activity, household formation, parenthood, inactivity, etc. and (v) morbidity indicators out of survey data on self-perceived health status and disability by age and gender.

After a first and rather descriptive exploitation of the data gathered, we see that an overall picture emerges showing us an ageing process that deserves a much closer analysis well beyond its aggregate (or age groups) manifestations. An analysis focused on the

\footnotetext{
${ }^{1}$ Most of the data comes from the national Statistical Offices of the countries included although the AGIR teams have been responsible for gathering, documenting and manipulating the raw data. Where needed, these data has been completed with data from the Human Mortality Database of University of California, Berkeley (USA), and Max Planck Institute for Demographic Research (Germany) [Available at www.mortality.org or www.humanmortality.de]. Finally, data from the database "La conjoncture des pays développés en chiffres" of the Institut National d'Études Démographiques (available at http://www.ined.fr/bdd/demogr/\#) has provided us with valuable data for all countries included here.
} 
individual and biologic aspects of ageing. These aspects are having profound impact on the way individuals and households organise their lifecycle.

European and other western countries, that completed their major demographic transition of the modern era well before the mid of the twentieth century, initiated almost without interruption a "second demographic transition" (van de Kaa, 1987) that has lasted for almost half a century. This second transition can be characterised by a sharp decline in fertility as rapid change in lifestyles and family/work arrangements took place after the births boom of WWII post-war. A pronounced ageing trend is now on course in these nations so that the age structure of the population as well as any other indicator concerning basic individual and aggregate lifecycle landmarks display a dramatic record of change that will most likely not be interrupted in the coming decades. These trends, in turn, will trigger intense adaptation both from individuals themselves and also from existing institutions resulting in behavioural change to cope with new challenges, limiting risks and enhancing opportunities.

Concerning demography we are interested in population dynamics as defined by vegetative forces, that is, births and deaths. We also deal in more detail with survival and longevity, as experienced in Europe in the last half century in order to ascertain whether it is the absolute limit to human life or, rather, the fact that more and more people reach extreme ages what drives the current ageing process. Two other phenomena require our interest when focusing in the circumstances among which ageing is taking place at present. On the one hand, the fact that typical "lifecourses" in western countries are witnessing seemingly contradictory developments concerning, for instance, life duration and early retirement or other lifecycle landmarks. On the other hand, and most important, the issue of how healthy and/or disability free are the extra years that otherwise medical services are, among other factors, helping the population as a whole to afford.

All these areas (populations, mortality, longevity, lifecourses and morbidity) are extremely intertwined and their interactions happen within a context of uninterrupted economic and technological advancement with which the former also interact. Our aim thus is to extract out of the abundant data on the areas just mentioned those facts, patterns and trends that better characterise the demographic process of western Europe in the last half century. 
We have organised the paper into three major sections on demography ( Section 2), lifecourses (Section 3) and morbidity (Section 4) that will help us to organise the summary description of our database and the discussion of the major findings and its comparative dimension. A final Section 5 will try to answer tentatively some questions that can be summarised in three very relevant ones indeed: (i) what means living longer? (ii) is living longer and working less mutually compatible? and (iii) means living longer living better? It turns out, ironically, that how we define ageing depends on the answers we may give to all these questions. ${ }^{2}$

\section{Demographic trends since 1950}

Western populations, as it is well known, have experienced a considerable change in the last half century. In EU countries, with few exceptions, population has not ceased to increase albeit at lower and lower rates due to the resulting effect of two compensating driving forces, that is, fewer births and increased life years. To this balance, immigration has been contributing on the plus side in most countries. Of course, each country has experienced different population dynamics, basically due to different timing in their babybooms and intensity of immigration flows, but all of them are now witnessing a considerable "ageing" of their populations. A process that will change to higher gears in the coming decades.

\subsection{Population}

Table 2.1 shows population figures (first column) and derived population indicators for ten EU countries and selected years 1950, 1975 and 2000. It can be seen that population growth has diminished everywhere although countries like France or the United Kingdom have succeeded in keeping a relatively high population growth through sustained fertility and immigration whereas Spain has most recently experienced high immigration flows and Ireland has both kept high fertility and reversed migration flows.

\footnotetext{
${ }^{2}$ The word "ageing" will be used through most of this paper with its standard meaning concerning the increased average age of a given population, or of its aged persons ratios computed around 65 years of age. Ageing however can be defined on the basis of a given general health and ability status of a representative individual which would result in a completely different picture.
} 


\begin{tabular}{|c|c|c|c|c|c|c|c|}
\hline \multicolumn{8}{|c|}{$\begin{array}{c}\text { Table } 2.1 \\
\text { Population indicators for (selected) EU count }\end{array}$} \\
\hline & Year & $\begin{array}{c}\text { Total } \\
\text { population } \\
\text { (a) }\end{array}$ & $\begin{array}{c}\text { Population } \\
\text { growth } \\
(\%)\end{array}$ & $\begin{array}{c}\text { Females } \\
\text { to males } \\
\text { ratio }\end{array}$ & $\begin{array}{l}\text { Support } \\
\text { ratio (b) }\end{array}$ & $\begin{array}{c}\text { Aged } \\
\text { Ratio (c) }\end{array}$ & $\begin{array}{l}\text { Average } \\
\text { age }\end{array}$ \\
\hline \multirow{3}{*}{ Belgium } & 1950 & 8,645 & 0.30 & 1.033 & 6.10 & 11.12 & 35.45 \\
\hline & 1975 & 9,807 & 0.24 & 1.043 & 4.59 & 13.96 & 35.82 \\
\hline & 2000 & 10,263 & 0.24 & 1.045 & 3.89 & 16.85 & 39.30 \\
\hline \multirow{3}{*}{ Denmark } & 1950 & 4,252 & 0.96 & 1.016 & 7.24 & 8.96 & 32.54 \\
\hline & 1975 & 5,055 & 0.38 & 1.019 & 4.83 & 13.26 & 35.40 \\
\hline & 2000 & 5,368 & 0.36 & 1.023 & 4.50 & 14.83 & 38.76 \\
\hline \multirow{3}{*}{ Germany } & 1950 & 69,346 & 0.63 & 1.170 & 6.90 & 9.73 & 34.64 \\
\hline & 1975 & 78,465 & -0.53 & 1.109 & 4.26 & 14.97 & 36.56 \\
\hline & 2000 & 82,038 & -0.15 & 1.054 & 4.17 & 16.32 & 40.36 \\
\hline \multirow{3}{*}{ Spain } & 1950 & 30,583 & & & & & \\
\hline & 1975 & 35,813 & 1.11 & 1.044 & 5.91 & 10.52 & 32.68 \\
\hline & 2000 & 40,122 & 0.98 & 1.043 & 4.04 & 16.93 & 39.35 \\
\hline \multirow{3}{*}{ Finland } & 1950 & 3,986 & 1.31 & 0.988 & 9.61 & 6.64 & 29.74 \\
\hline & 1975 & 4,720 & 0.22 & 0.974 & 6.26 & 10.77 & 33.95 \\
\hline & 2000 & 5,181 & 0.19 & 1.007 & 4.46 & 15.00 & 38.88 \\
\hline \multirow{3}{*}{ France } & 1950 & 41,614 & 0.87 & 1.081 & 5.83 & 11.36 & 34.81 \\
\hline & 1975 & 52,606 & 0.55 & 1.041 & 4.67 & 13.40 & 34.52 \\
\hline & 2000 & 58,754 & 0.41 & 1.054 & 4.18 & 15.61 & 37.79 \\
\hline \multirow{3}{*}{ Ireland } & 1950 & 2,961 & -0.31 & 0.965 & & & \\
\hline & 1975 & 2,978 & 8.21 & 0.991 & 5.20 & 11.08 & 31.67 \\
\hline & 2000 & 3,787 & 1.51 & 1.014 & 5.99 & 11.16 & 34.54 \\
\hline \multirow{3}{*}{ Italy } & 1950 & 47,516 & 0.53 & 1.043 & 8.01 & 8.20 & 31.48 \\
\hline & 1975 & 55,293 & 0.66 & 1.047 & 5.34 & 11.93 & 34.50 \\
\hline & 2000 & 57,680 & 0.12 & 1.060 & 3.76 & 17.97 & 40.86 \\
\hline \multirow{3}{*}{ Sweden } & 1950 & 6,978 & 0.91 & 1.009 & 6.58 & 10.14 & 34.36 \\
\hline & 1975 & 8,193 & 0.39 & 1.011 & 4.10 & 15.69 & 37.74 \\
\hline & 2000 & 8,872 & 0.16 & 1.023 & 3.64 & 17.71 & 40.26 \\
\hline \multirow{3}{*}{$\begin{array}{l}\text { United } \\
\text { Kingdom }\end{array}$} & 1950 & 50,490 & 0.70 & 1.083 & 6.13 & 10.93 & 35.19 \\
\hline & 1975 & 56,231 & -0.01 & 1.056 & 4.44 & 14.13 & 35.97 \\
\hline & 2000 & 59,756 & 0.43 & 1.028 & 4.20 & 15.59 & 38.32 \\
\hline
\end{tabular}

(a) As of $31^{\text {st }}$ December, in thousands

(b) Number of persons of between 15 and 64 years of age per person of 65 or more.

(c) Number of persons of 65 or more per 100 persons of any age.

Note. Data in this table come from the following sources: National Statistical Offices (Provided by the AGIR-WP1 Teams), INED (www.ined.fr/bdd/demogr/) and the Human Mortality Database [University of California, Berkeley (USA) and Max Planck Institute for Demographic Research (Germany). Available at www.mortality.org or www.humanmortality.de (data downladed on May 2003)].

Although in a typical year, everywhere, more boys are born than girls, the different death probabilities that affect each group cause that with few exceptions the gender balance in a given population tips towards the female side. This is apparent in Table 2.1 (third column) in the four largest countries of the EU, although Nordic countries and Ireland have 
kept in the last decades a closer balance among genders that has been nevertheless tipping recently towards the more standard female bias (Figure 2.3).

As for total population, Figure 2.1 shows more eloquently how in general population size has been growing less rapidly since 1975 after when the oil crisis almost stopped migration flows and fertility started to decline dramatically. More recently many EU countries have been experiencing intense immigration flows what has resulted in an stimulus to population growth.

Figure 2.1

Total population of (selected) EU countries 1950-2000

(As of $31^{\text {st }}$ December, x1000)

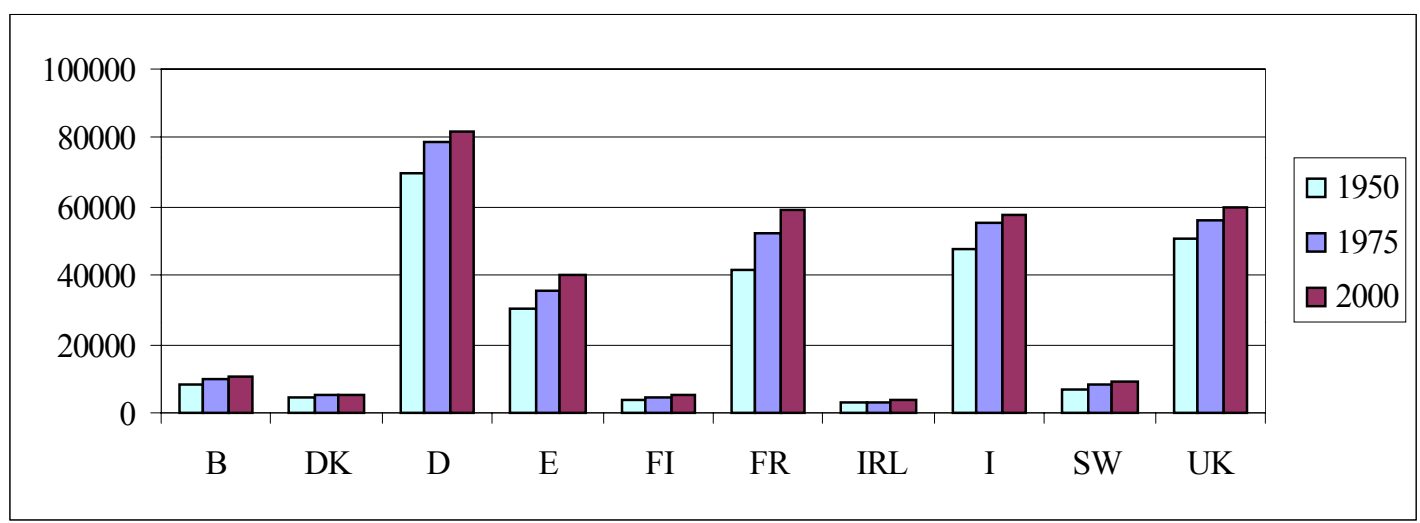

Source: Table 2.1

The dynamics of total population hides however the dramatic developments that have been the norm in EU countries concerning the age structure of the population and related age ratios. Table 2.1 (columns fourth to sixth) shows three of these indicators: the "support ratio" which is the inverse of the aged dependency ratio, the "aged (persons) ratio" and the average age of the population. ${ }^{3}$ Two different trends can be observed around these indicators that are also pictured separately in Figures 2.2 to 2.4.

Support ratios diminished appreciably everywhere between 1950 and 1975. That is, the number of persons of working age per person aged 65 or more fell from 6 and more to between 4 to 5 and fell again between 1975 and 2000 to around 4. In countries like Belgium, Sweden and Italy this ratio is now well below 4 whereas in Ireland it has increased to a very high level of 6 .

\footnotetext{
${ }^{3}$ See notes to Table 2.1 for definitions.
} 
Figure 2.2

Support ratio in (selected) EU countries 1950-2000

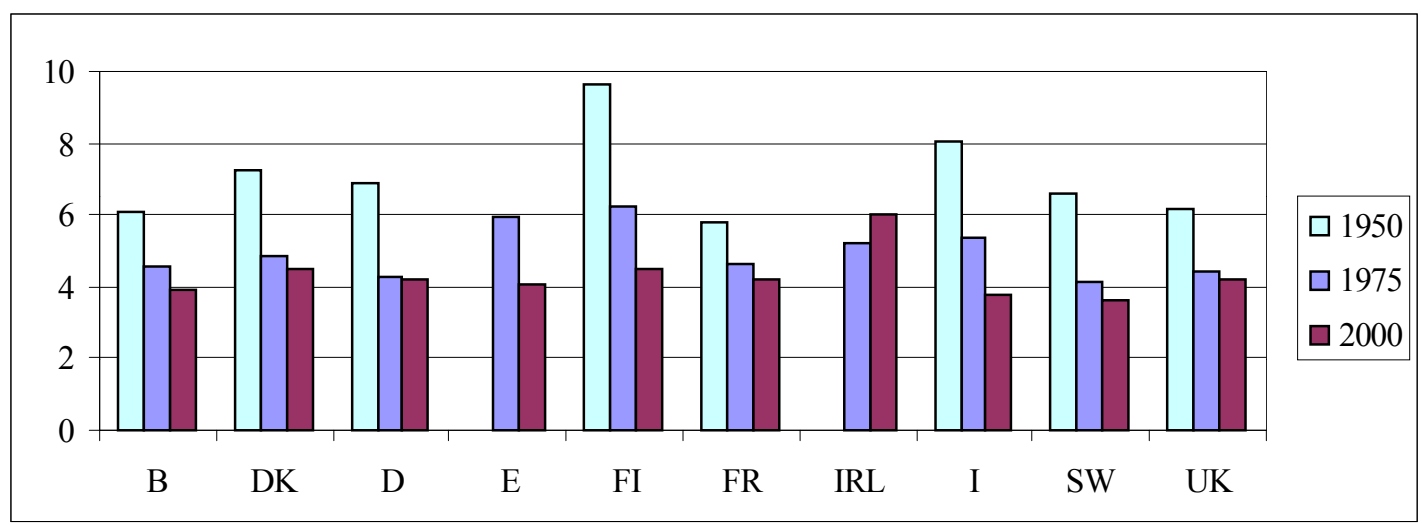

Source: Table 2.1 (see also Table for definition)

Ageing however, has advanced in a different and more mixed fashion as can be seen in Figure 2.3. With the exception of Ireland, the share of persons aged 65 and more in total population has doubled from around 8 (with large variance however) in 1950 till now. This development has been more rapid in the sixties and seventies than afterwards in Denmark, Germany, Sweden or the United Kingdom whereas in the rest of the countries considered the pace has been more regular and particularly intense in Italy or Spain. Ireland has hardly experienced that kind of ageing in the recent decades.

Figure 2.3

Aged ratio in (selected) EU countries 1950-2000 (in \%)

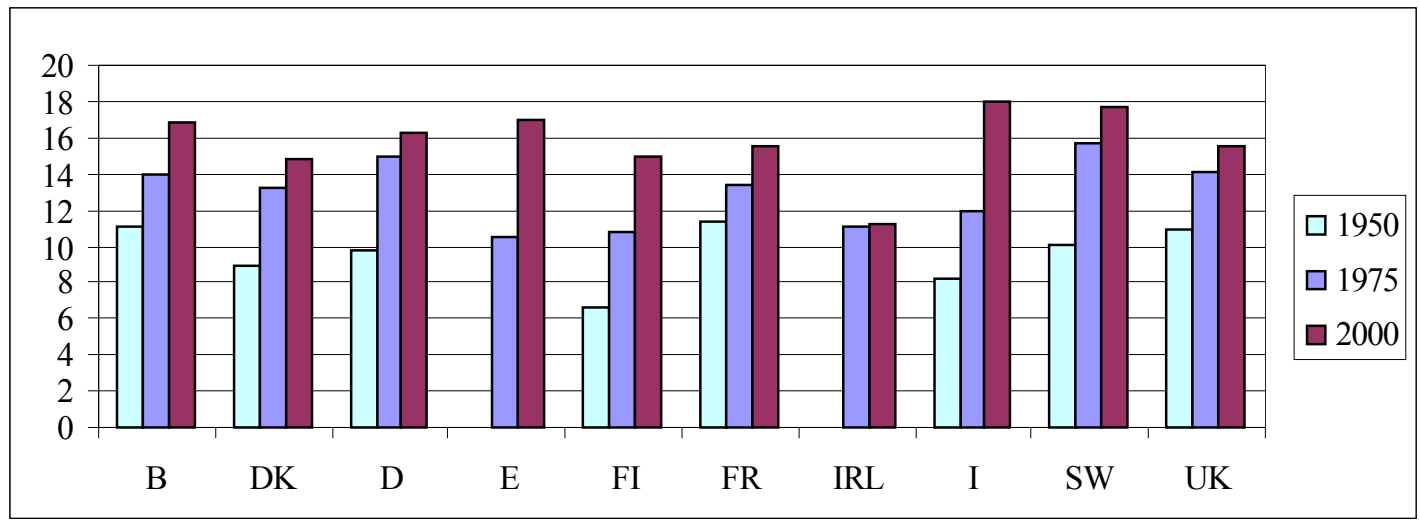

Source: Table 2.1 (see also Table for definition)

When we define ageing though average age of the population, we observe that it has been happening particularly since 1975. In 1950, average age of the population in most 
countries stayed around 33.5 years, increased to almost 35 years in 1975 and more than doubled this increase in the period 1975-2000 to reach the almost 39 years observed at present. This is probably the single best indicator of how a given population ages through time in the sense expressed before that ageing is just getting older in terms of pure age.

Figure 2.4

Average age of the population in (selected) EU countries 1950-2000

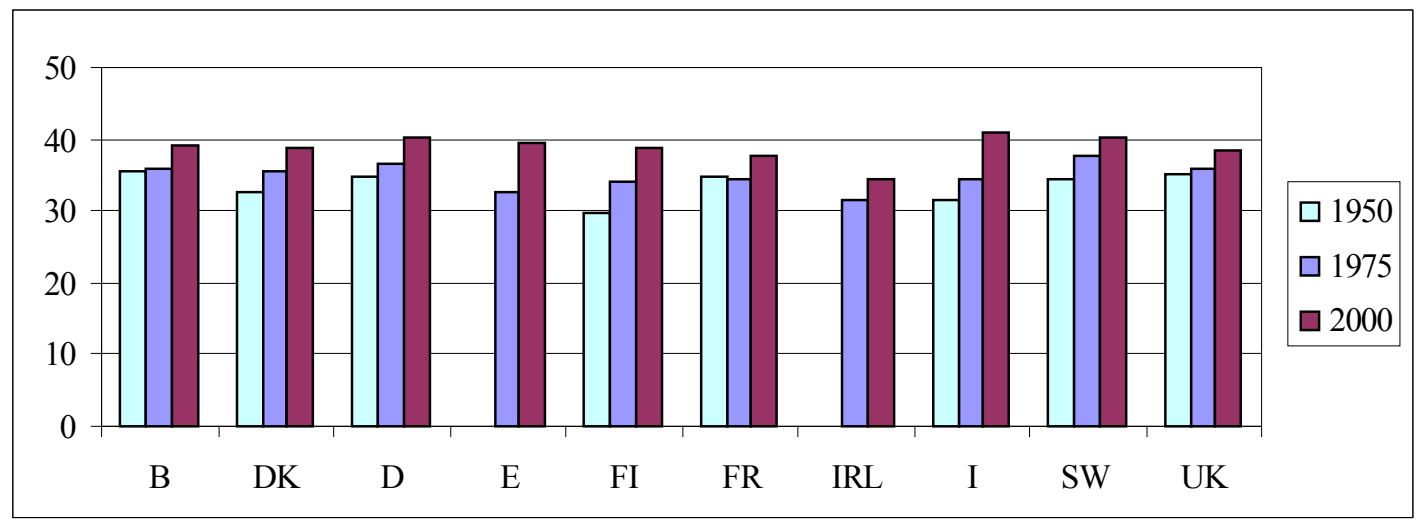

Source: Table 2.1

Whereas age ratios may have a more complex dynamics depending on the cutting age at which the line is drawn, average age computations give every age the corresponding cohort weight and thus captures in a continuous fashion the passage of generations of different age. We will come back latter to this point when discussing population projections.

\subsection{Births and fertility}

Letting apart migrations, that we are not considering in this report, births and deaths determine the vegetative movement of populations. Both developments have suffered dramatic changes in EU countries since 1950. To be sure, the demographic transition that Western countries initiated in the first half of the XIX century has been unparalleled by the developments since 1950 , but what has been different is the fact that fertility rates fell below replacement levels around 1970. This development holds the key to the ageing process that will accelerate in the near decades in EU countries, although unexpected change in either compression or expansion of survival will undoubtedly exacerbate ageing in the longer term. 
Table 2.2 shows absolute numbers of births and derived indicators for our ten EU countries in 1950, 1975 and 2000. Most countries initiated their baby-booms just after World War II and finished them around 1970 (first column). Almost in every countries male births exceed female ones by about $5.5 \%$ and the evidence shows that this fact is getting an even more strong profile in a majority of countries (third column). Birth rates suffered in that period most of their decline in the second half of the twentieth century and nearly stabilised afterwards (second column). Fertility rates, correspondingly, fell below replacement levels also around 1970 (fourth column). 


\begin{tabular}{|c|c|c|c|c|c|}
\hline \multicolumn{6}{|c|}{$\begin{array}{c}\text { Table } 2.2 \\
\text { Births and fertility indicators for (selected) EU countries 1950-2000 }\end{array}$} \\
\hline & Year & Births & $\begin{array}{l}\text { Birth rate } \\
\text { (a) }\end{array}$ & $\begin{array}{l}\text { Males to } \\
\text { females }\end{array}$ & $\begin{array}{l}\text { Fertility } \\
\text { rate }\end{array}$ \\
\hline \multirow{3}{*}{ Belgium } & 1950 & 145,672 & 16.85 & 1.055 & 2.34 \\
\hline & 1975 & 119,693 & 12.20 & 1.059 & 1.74 \\
\hline & 2000 & 114,883 & 11.19 & 1.048 & 1.66 \\
\hline \multirow{3}{*}{ Denmark } & 1950 & 79,558 & 18.71 & 1.049 & 2.57 \\
\hline & 1975 & 72,071 & 14.26 & 1.044 & 1.92 \\
\hline & 2000 & 67,081 & 12.59 & 1.055 & 1.77 \\
\hline \multirow{3}{*}{ Germany } & 1950 & $1,116,701$ & 16.10 & 1.074 & 2.1 \\
\hline & 1975 & 782,310 & 9.97 & 1.061 & 1.48 \\
\hline & 2000 & 770,744 & 9.38 & 1.058 & 1.36 \\
\hline \multirow{3}{*}{ Spain } & 1950 & 565,378 & 20.11 & 1.055 & 2.48 \\
\hline & 1975 & 669,378 & 18.69 & 1.072 & 2.80 \\
\hline & 2000 & 397,632 & 9.91 & 1.071 & 1.24 \\
\hline \multirow{3}{*}{ Finland } & 1950 & 98,065 & 24.60 & 1.055 & 3.16 \\
\hline & 1975 & 65,719 & 13.92 & 1.060 & 1.68 \\
\hline & 2000 & 56,742 & 10.95 & 1.064 & 1.73 \\
\hline \multirow{3}{*}{ France } & 1950 & 862,310 & 20.60 & 1.051 & 2.93 \\
\hline & 1975 & 745,065 & 14.10 & 1.051 & 1.93 \\
\hline & 2000 & 726,768 & 13.20 & 1.055 & 1.89 \\
\hline \multirow{3}{*}{ Ireland } & 1950 & 63,565 & 21.4 & & 3.41 \\
\hline & 1975 & 67,178 & 21.7 & & 3.43 \\
\hline & 2000 & 54,239 & 14.4 & & 1.89 \\
\hline \multirow{3}{*}{ Italy } & 1950 & 908,622 & 18.12 & 1.058 & 2.5 \\
\hline & 1975 & 827,852 & 14.97 & 1.061 & 2.17 \\
\hline & 2000 & 538,999 & 9.34 & 1.064 & 1.23 \\
\hline \multirow{3}{*}{ Sweden } & 1950 & 115,414 & 16.5 & 1.070 & 2.28 \\
\hline & 1975 & 103,632 & 12.65 & 1.057 & 1.77 \\
\hline & 2000 & 90,441 & 10.19 & 1.064 & 1.54 \\
\hline \multirow{3}{*}{ United Kingdom } & 1950 & 818421 & 16.2 & 1.062 & \\
\hline & 1975 & 697,518 & 12.40 & 1.062 & 1.81 \\
\hline & 2000 & 679,029 & 11.4 & 1.053 & 1.65 \\
\hline \multicolumn{6}{|c|}{$\begin{array}{l}\text { (a) Number of births per } 1000 \text { population } \\
\text { Note. Data in this table come from the following sources: National Statistical } \\
\text { Offices (provided by the AGIR-WP1 Teams), INED } \\
\text { (http://www.ined.fr/bdd/demogr/) and the Human Mortality Database [University } \\
\text { of California, Berkeley (USA) and Max Planck Institute for Demographic Research } \\
\text { (Germany). Available at www.mortality.org or www.humanmortality.de (data } \\
\text { downladed on May 2003)]. }\end{array}$} \\
\hline
\end{tabular}

Figure 2.5 allows a closer approach to country differences. Of course, the absolute numbers shown concerning births tell us immediately about "large" and "small" countries in the EU in terms of population, but above all tell us about the timing of the birth-booms in every country. Belgium Germany, Finland, France, and the United Kingdom had ended their booms well by 1975 keeping afterwards stable number of total births. Spain initiated 
her baby-boom in the mid sixties an ended it after 1975 to start a fast decline in fertility that almost halved the size of new born cohorts in less than twenty years. Italy too has followed a similar pattern of recent decline in fertility although joined the European baby-boom just described much earlier.

Figure 2.5

Total Births in (selected) EU countries 1950-2000

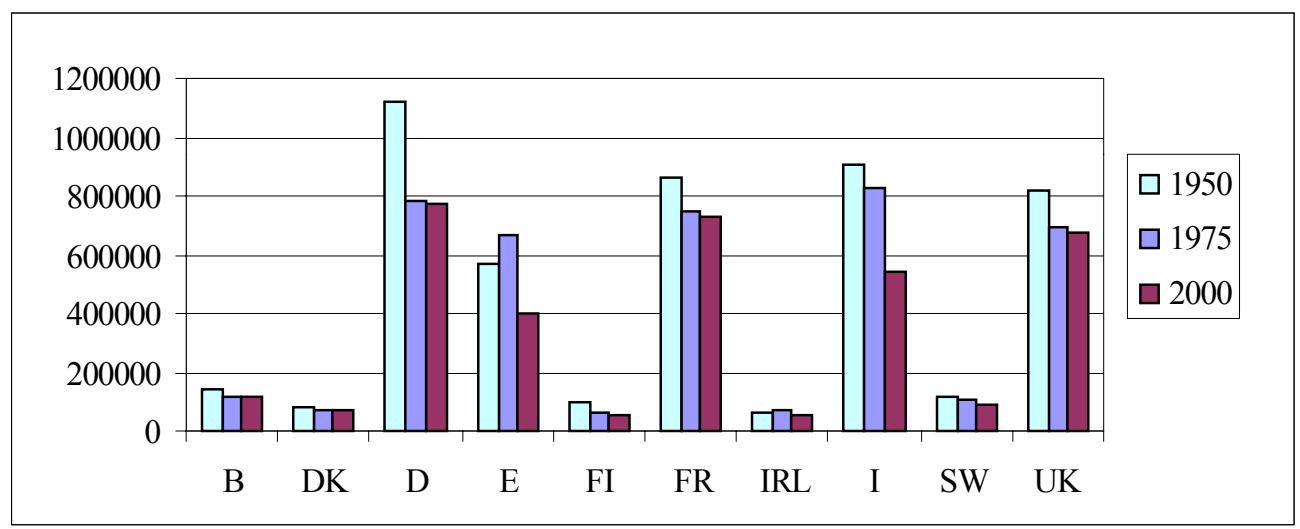

Source: Table 2.2

Around 1950, birth rates were well above 15 births per thousand inhabitants with countries like Spain, Finland, France and Ireland above the level of 20. Fifty tears later, birth rates in most countries stand around 10 per thousand with the exception of France and Ireland that are closer to 15 rather. Again, in most countries, the larger part of this development happened before 1975 except in Spain, Ireland and Italy where it took place mostly in the recent decades (Figure 2.6).

Figure 2.6

Birth rate in (selected) EU countries 1950-2000

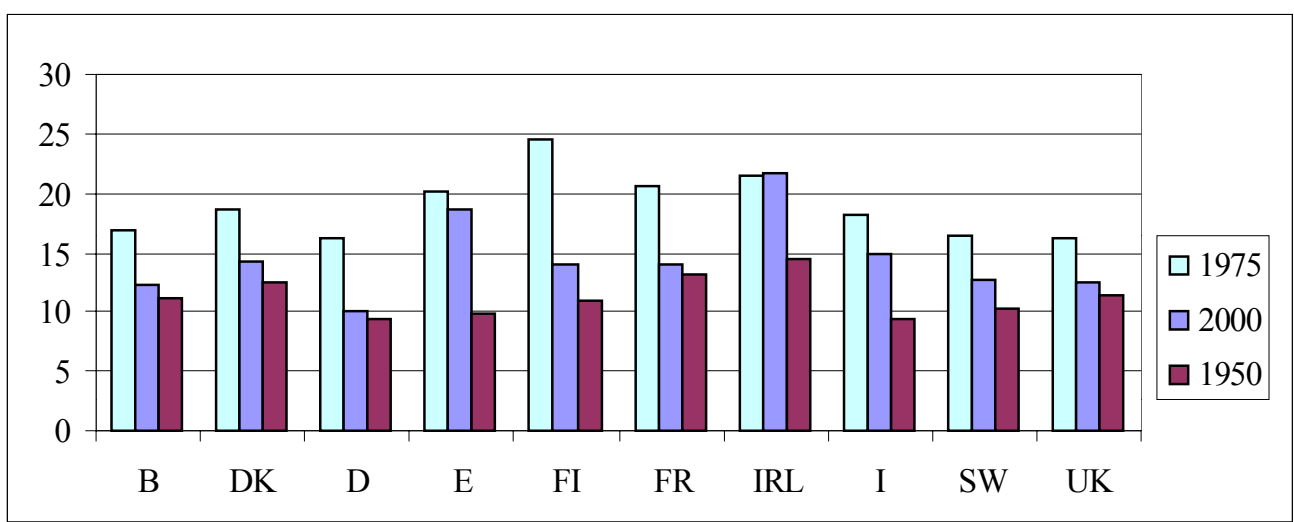

Source: Table 2.2 (see also Table for definition) 
Everywhere male births exceed female ones by between 5 and 7 per cent, despite de fact that within the whole population women are more numerous than men due to gender related death risks. Although not everywhere, this gap has been growing steadily in the last 50 years. The exceptions, among the countries considered, are Belgium, Germany, Sweden and the United Kingdom.

The sharpest differences however can be seen when comparing fertility ratios (Figure 2.7). Again, in almost every country fertility ratios fell from an (unweighted) average level of 2.5 in 1950 to 2, just below the replacement level, in 1975 and 1.6 in 2000. What seems an stead decline however hides the fact that countries like Spain and Ireland kept or even increased their fertility rates all through the 1050-1975 period while the rest actually decreased their fertility rates much rapidly in the same period. In Spain and Italy, fertility bottomed at nearly 1 child per women during the nineties to regain slightly higher levels in the recent past. Again, the Spanish, Irish and Italian cases explain the fall in average fertility for the whole group for fertility rates did not change much in the rest of the countries in the $1975-2000$ period.

Figure 2.7

Fertility ratio in (selected) EU countries 1950-2000

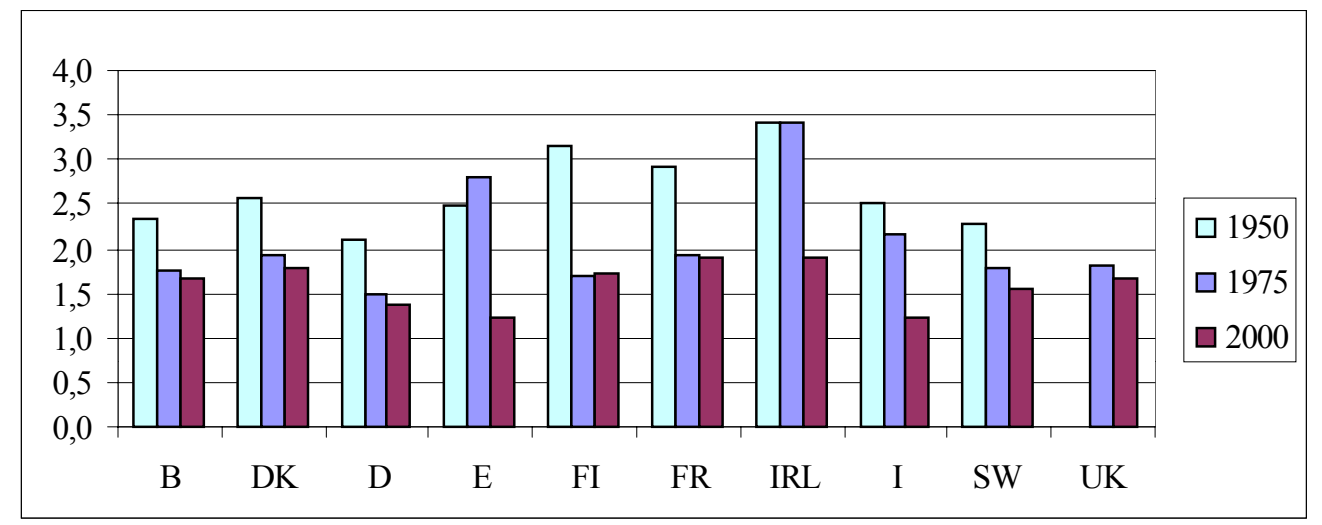

Source: Table 2.2

\subsection{Mortality}

Falling mortality has been, jointly with lower fertility, the driving force of the demographic transition that has taken place in Western Europe since the fifties last century. But as fertility rates bounced some few years ago to start a modest upwards run, mortality risk continues to diminish everywhere for almost all ages. Mortality is measured in 
different ways. Measured as a per cent or per thousand rate against total population in a given country, mortality could go up as population grows older thus hiding more genuine developments. In this section we will approach the clear-cut phenomenon of falling mortality looking first at observed death risks by age and its evolution through time and latter we will analyse survival probabilities computed for different EU countries out of their respective life tables.

Up to the sixties last century, falling infant mortality was the mayor cause of longer survival among individuals. More recently increased survival at high or even extreme ages has taken the lead. Even since around 1975 observed death risk at almost any age has fallen in a significant amount everywhere. We compute this risk as the number of observed deaths of given age over total population of that age in any particular year. However, in order to make meaningful comparisons between countries and through time we use the ratio between observed risks at two extreme years in a given period of time (2000 over 1975) to summarise in a single indicator a factor of change of that standard measure of mortality. Table 2.3 shows this ratio computed for nine EU countries and selected ages and Figure 2.8 displays the age profile of this ratio. Remember that a value of, say, 0.7 for the ratio at age 17 means that the death probability of an individual of that age has fallen in 2000 down to a 70 per cent of its value in 1975. In particular, it can be seen that in the last twenty five years, infant mortality risk has fallen in most EU countries to a third of what it was in 1975 , or that adult mortality risk (ages 20 to 50) has fallen in the same period by between 30 and 35 per cent. Mortality risk at higher ages (60 to 80) has fallen even more than mid age mortality risk reaching nearly 60 per cent of its level in 1975. 
Table 2.3

Mortality risk in 2000 relative to its value in 1975 for selected ages - EU countries

\begin{tabular}{|c|c|c|c|c|c|c|c|c|c|c|}
\hline & B & DK & D & E & F & FIN & IT & SW & UK & Average \\
\hline 0 & 0.30 & 0.45 & 0.24 & 0.23 & 0.36 & 0.38 & 0.24 & 0.40 & 0.43 & 0.32 \\
\hline 5 & 0.18 & 0.22 & 0.23 & 0.39 & 0.40 & 0.36 & 0.43 & 0.26 & 0.37 & 0.29 \\
\hline 10 & 0.39 & 0.44 & 0.43 & 0.50 & 0.46 & 0.49 & 0.47 & 0.36 & 0.54 & 0.45 \\
\hline 20 & 0.74 & 0.54 & 0.52 & 0.79 & 0.57 & 0.87 & 0.88 & 0.75 & 0.73 & 0.68 \\
\hline 30 & 0.72 & 0.70 & 0.42 & 0.77 & 0.85 & 0.74 & 0.96 & 0.50 & 0.99 & 0.69 \\
\hline 40 & 0.70 & 0.73 & 0.66 & 0.85 & 0.72 & 0.66 & 0.67 & 0.45 & 0.78 & 0.67 \\
\hline 50 & 0.73 & 0.80 & 0.53 & 0.66 & 0.68 & 0.67 & 0.57 & 0.56 & 0.64 & 0.64 \\
\hline 60 & 0.55 & 0.71 & 0.40 & 0.64 & 0.72 & 0.63 & 0.59 & 0.67 & 0.63 & 0.60 \\
\hline 70 & 0.53 & 0.87 & 0.51 & 0.59 & 0.60 & 0.59 & 0.74 & 0.63 & 0.67 & 0.62 \\
\hline 80 & 0.59 & 0.81 & 0.41 & 0.60 & 0.63 & 0.63 & 0.93 & 0.67 & 0.70 & 0.63 \\
\hline
\end{tabular}

Source: Own computations based on data from national Statistical Offices completed with data from www.mortality.org.

Figure 2.8 allows a better perspective of the age pattern of the mortality risk ratios for each country. It is apparent that major gains have been the norm at ages below 10 and between 50 and 80 . At extreme ages, computations lack precision due to the rarity of cases to be dealt with, but from the figure we can infer that as age increases gains in decreased mortality risk get smaller and smaller. This is an indication of very limited "expansion" of human life, almost null at extreme ages, whereas the observed gains at ages 50 to 80 is an strong evidence of "compression" of the survival curve. In other words, populations age not because the observed limit to human life increases, but because more and more people reach extreme ages below the limiting age whatever this limit age is. 


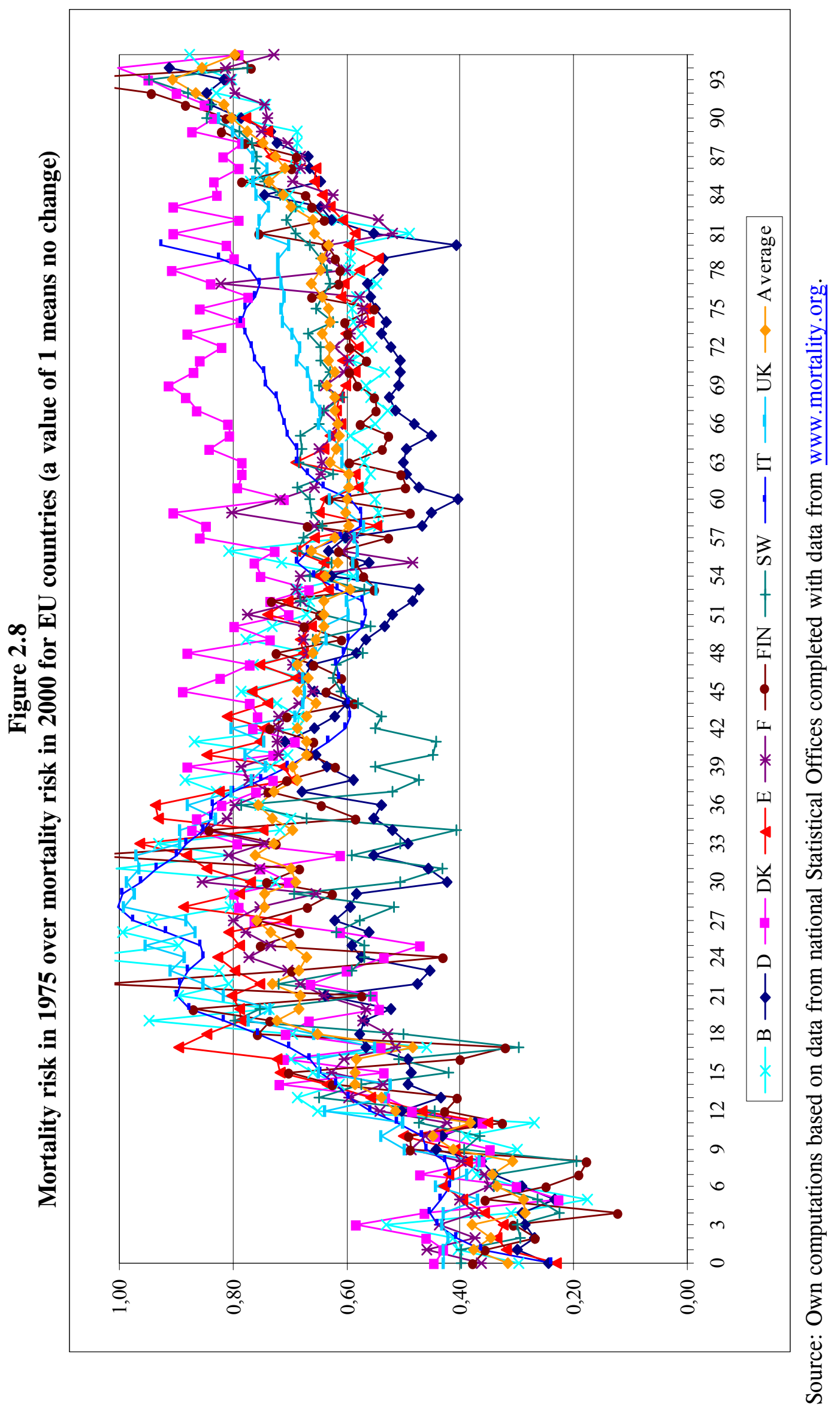


Countries where gains of the sort described above have been Germany, Finland and Sweden, while Denmark, the United Kingdom and Italy have performed more poorly on this account. Spain or Belgium have had mixed results performing below average (less gains) at ages until 45 and above average (more gains) after that age.

\section{Survivors}

The significant gains in survival have had also a parallel development in what concerns the increase of persons of ages above 50 years everywhere. We have used the life tables of EU countries, available many of them since mid past century, to compute a simple ratio of theoretical survivors (out of a generation of 100,000 individuals of both genres) of any age in 2000 with respect to same age survivors in 1975 or 1950 , given data availability. These ratios are shown in Table 2.4 for selected ages.

\begin{tabular}{|c|c|c|c|c|c|c|c|c|c|c|c|}
\hline \multicolumn{12}{|c|}{$\begin{array}{c}\text { Table } 2.4 \\
\text { Survivors ratio (2000 over ca. } 1975 \text { or ca. } 1950) \text { by selected age }- \text { EU countries }\end{array}$} \\
\hline & \multicolumn{6}{|c|}{ Ratios 2000 over ca. 1950} & \multicolumn{5}{|c|}{ Ratios 2000 over ca. 1975} \\
\hline & B & DK & $\begin{array}{c}\mathrm{D} \\
\text { (West) }\end{array}$ & $\mathrm{F}$ & SW & Average & $\mathrm{E}$ & FI & IT & UK & Average \\
\hline 1 & 1.03 & 1.03 & 1.04 & 1.05 & 1.02 & 1.03 & 1.01 & 1.01 & 1.02 & 1.01 & 1.01 \\
\hline 10 & 1.06 & 1.03 & 1.04 & 1.06 & 1.02 & 1.04 & 1.02 & 1.01 & 1.02 & 1.01 & 1.01 \\
\hline 20 & 1.07 & 1.04 & 1.05 & 1.07 & 1.03 & 1.05 & 1.02 & 1.01 & 1.02 & 1.01 & 1.02 \\
\hline 30 & 1.08 & 1.04 & 1.06 & 1.08 & 1.04 & 1.06 & 1.02 & 1.02 & 1.03 & 1.01 & 1.02 \\
\hline 40 & 1.10 & 1.05 & 1.07 & 1.09 & 1.05 & 1.07 & 1.02 & 1.02 & 1.03 & 1.01 & 1.02 \\
\hline 50 & 1.14 & 1.06 & 1.08 & 1.13 & 1.06 & 1.09 & 1.03 & 1.04 & 1.04 & 1.02 & 1.03 \\
\hline 60 & 1.21 & 1.08 & 1.13 & 1.20 & 1.11 & 1.15 & 1.06 & 1.08 & 1.08 & 1.05 & 1.07 \\
\hline 70 & 1.40 & 1.15 & 1.27 & 1.39 & 1.24 & 1.29 & 1.14 & 1.22 & 1.16 & 1.12 & 1.16 \\
\hline 80 & 1.95 & 1.46 & 1.87 & 2.08 & 1.75 & 1.82 & 1.44 & 1.56 & 1.40 & 1.23 & 1.41 \\
\hline 90 & 3.84 & 3.18 & 4.75 & 5.17 & 4.02 & 4.19 & 2.42 & 2.55 & 2.25 & 1.43 & 2.16 \\
\hline 100 & 6.83 & 15.31 & 21.33 & 14.32 & 14.25 & 14.41 & & 3.15 & 7.74 & & 5.44 \\
\hline \multicolumn{12}{|c|}{$\begin{array}{l}\text { Note. Ratios computed at extreme ages should be regarded with caution given the small numbers on } \\
\text { which their computation is based. } \\
\text { Source: Own computations based on data from national Statistical Offices completed with data from } \\
\text { www.mortality.org. }\end{array}$} \\
\hline
\end{tabular}

Given that mortality risk is typically low at ages below 60, even significant decreases do not make the number of survivors to increase dramatically. In fact below that age, it is hard to see that survivors of a typical generation born today would increase above 10 (20) per cent of those estimated for a typical generation born 25 (50) years ago. However, above 60 years of age, the survivors ratio may increase dramatically. Fifty years 
ago, typically, only $30 \%$ of a theoretical generation was expected to be alive at age 80 . For a generation born today up to 60 per cent of its members could reach that age. This means a factor of 2 , or a factor of 5 for age 90 , and so on. Until, of course, past the limit age of a human life, the ration would collapse.

After certain ages the survivors ratio increase in an exponential way, even through more recent periods. Again, of course, the fact that more and more people survives until the limit age, means that one should not expect any further dramatic increase in survivors ratios in the next decades unless we consider very high ages. But the run is still long as a generation born in 2050 would still keep 80 per cent of its numbers in 2130 as compared to 60 percent for a generation born today in a "business as usual" scenario, a factor of 1.33 that compares relatively well with a factor of 1.4 for the period $1975-2000$ or 1.8 for the period 1950-2000. France, Belgium and (West) Germany have pioneered, in general, these developments.

\subsection{Longevity}

After having looked at mortality and survival developments in EU countries in the last few decades, we turn to the description and analysis of various indicators of longevity. Representative individuals in western countries live longer and longer as it is well known and can be documented thoroughly through the data so far discussed in this report. Moreover, it is also apparent that, rather than a higher limit age of human life, what causes the ageing of the population is the fact that more and more people reaches extreme ages below that limit.

There are a number of ways in which we can approach longevity, that is, the growing of age of representative individuals. One important corollary of the causes of ageing discussed before is that the distribution of the duration of individual life for the members of a given generation is becoming more "egalitarian" with the extreme case being all members of a theoretical generation living exactly until the limiting age. This, however, as discussed before, is still far from being the case.

In order to discuss this issue as documented from the data gathered under the AGIR project, we have obtained several measures of longevity. They are presented and defined in Table 2.5 and Figures 2.9 to 2.14. In order to provide a compact presentation, Table 2.5 only shows selected years, whilst each graph refers to one indicator at a time for those 
same selected years except Figure 2.14 that refers to the whole period 1950-2000 for record age. It has been argued already about the fact that more and more people reach extreme ages, the discussion in this section is a bit different and refers to the evolution of those extreme ages irrespective of the number of people that reaches them.

The most generally accepted measure of longevity is life expectancy, at birth or at later ages. It can be seen in Table 2.5 that this indicator has not ceased to increase in the last decades everywhere. However this indicator, like most of which we will define later on, is computed out of lifetables results for theoretical generations born in any year. There is not apparent deceleration in this trend for, on average, life expectancy has augmented of 5 years of age every 25 time years. 


\begin{tabular}{|c|c|c|c|c|c|c|}
\hline \multicolumn{7}{|c|}{$\begin{array}{c}\text { Table } 2.5 \\
\text { Longevity indicators } 1950-2000-\text { EU countries }\end{array}$} \\
\hline & Year & $\begin{array}{c}\text { Life expectancy } \\
\text { at birth (a) }\end{array}$ & $\begin{array}{c}\text { Median } \\
\text { duration }(b)\end{array}$ & $\begin{array}{c}\text { Modal } \\
\text { duration (c) }\end{array}$ & $\begin{array}{c}\text { Life endurance } \\
\text { (d) }\end{array}$ & $\begin{array}{l}\text { Record } \\
\text { Age (e) }\end{array}$ \\
\hline \multirow{3}{*}{ Belgium } & 1950 & 67.4 & 73.4 & 76 & 87.0 & \\
\hline & 1975 & 72.5 & 76.1 & 79 & 88.7 & 106 \\
\hline & 2000 & 78.3 & 81.7 & 86 & 93.1 & 110 \\
\hline \multirow{3}{*}{ Denmark } & 1950 & 70.3 & 75.3 & 77 & 87.3 & 102 \\
\hline & 1975 & 74.1 & 77.5 & 82 & 90.4 & 108 \\
\hline & 2000 & 76.8 & 79.5 & 80 & 92.3 & 110 \\
\hline \multirow{3}{*}{ Germany } & 1950 & 66.6 & 74.0 & 77 & 86.0 & \\
\hline & 1975 & 71.5 & 76.0 & 79 & 88.0 & 107 \\
\hline & 2000 & 77.9 & 81.0 & 83 & 93.0 & 112 \\
\hline \multirow{3}{*}{ Spain } & 1950 & & & & & \\
\hline & 1975 & 73.4 & 77.5 & 79 & 89.4 & 109 \\
\hline & 2000 & 79.1 & 82.6 & 87 & 93.4 & 110 \\
\hline \multirow{3}{*}{ Finland } & 1950 & & & & & 101 \\
\hline & 1975 & 71.9 & 75.5 & 78 & 88.4 & 107 \\
\hline & 2000 & 77.7 & 81.2 & 85 & 92.4 & 110 \\
\hline \multirow{3}{*}{ France } & 1950 & 66.4 & 73.0 & 78 & 86.7 & 107 \\
\hline & 1975 & 72.9 & 76.9 & 82 & 89.8 & 108 \\
\hline & 2000 & 78.5 & 82.3 & 87 & 93.9 & 122 \\
\hline \multirow{3}{*}{ Italy } & 1950 & & & & & 104 \\
\hline & 1975 & 72.6 & 76.0 & 81 & 88.0 & 108 \\
\hline & 2000 & 78.6 & 81.0 & 82 & 92.5 & 110 \\
\hline \multirow{3}{*}{ Sweden } & 1950 & 71.1 & 75.6 & 80 & 87.5 & 105 \\
\hline & 1975 & 75.0 & 78.3 & 82 & 90.3 & 109 \\
\hline & 2000 & 79.7 & 82.6 & 86 & 93.4 & 110 \\
\hline \multirow{3}{*}{$\begin{array}{l}\text { United } \\
\text { Kingdom }\end{array}$} & 1950 & & & & & \\
\hline & 1975 & 74.6 & 78.1 & 83 & 90.4 & 110 \\
\hline & 2000 & 77.9 & 81.8 & 84 & 90.6 & 115 \\
\hline \multicolumn{7}{|c|}{$\begin{array}{l}\text { (a) Average number of years that an individual born in a particular year is expected to live. } \\
\text { (b) Age at which fifty per cent of the generation numbers born in a given year will remain alive } \\
\text { (c) Age at which the maximum number of deaths of a generation born in a particular year would } \\
\text { occur (excluded infant mortality) } \\
\text { (d) Age at which ten per cent of the generation numbers born in a given year will remain alive } \\
\text { (e) Highest age of the distribution of observed deaths in a given year } \\
\text { Sources: Own computations based on data from national Statistical Offices completed with data } \\
\text { from www.mortality.org. }\end{array}$} \\
\hline
\end{tabular}

Figure 2.19 shows Sweden and Spain to have the highest life expectancies at birth (in 2000) and Denmark, Finland and the UK to have the lowest. Progress on that account has been pronounced also during the eighties and nineties in most EU countries. Of course, this development does not means that in the future life expectancies would augment as rapidly as in the past, for as the absolute limit of a human life remains unchanged, one should expect less and less margin to be left for further increases. Nevertheless, this absolute limit is not well known yet and in any case were we to place it at around 120 years 
of age, there is still a considerable run before life expectancies show a clearly decelerating pattern. Against this background can be discussed most of the longevity indicators whose description follows.

Figure 2.9

Life expectancy at birth (years) 1950-1975-2000 for EU countries

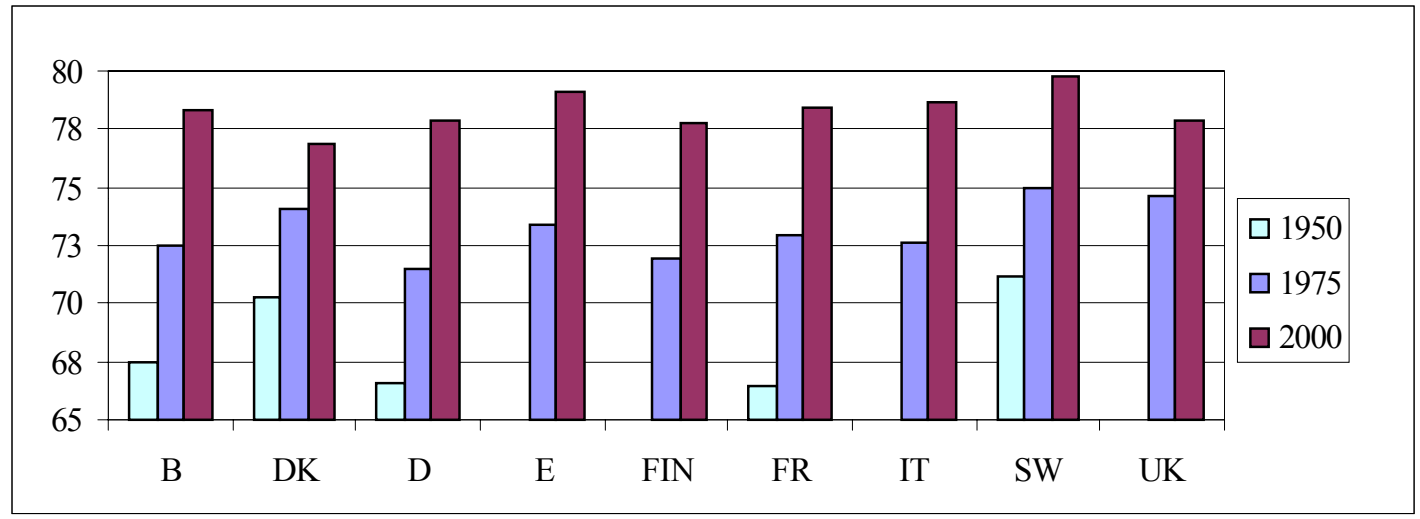

Source: Own computations based on data from national Statistical Offices completed with data from www.mortality.org.

In around 1950, a typical generation just born that year in western European countries would have exhausted half its numbers at age 74 or, said differently, individuals of that generation reaching their $74^{\text {th }}$ birthday would amount to half those born 74 years before. This is known as "median duration" of a given generation. In 1975, the corresponding age could be estimated as being about 3 years higher and still almost 4 years higher in 2000 with respect to 25 years earlier. This can be seen for different EU countries in Figure 2.10.

Again, these are theoretical estimates rather than observed ones for it is obvious we cannot observe yet, given those estimates, at what effective age those born in any particular country in 1950 would amount to half the numbers of 1950. All in all they show that survival, as discussed before, is considerably improving at mature ages. Median duration, on average, has been growing faster in the later decades than in the former in the last fifty years almost everywhere with the marked exception of Denmark. 
Figure 2.10

Median duration (age) 1950-1975-2000 for EU countries

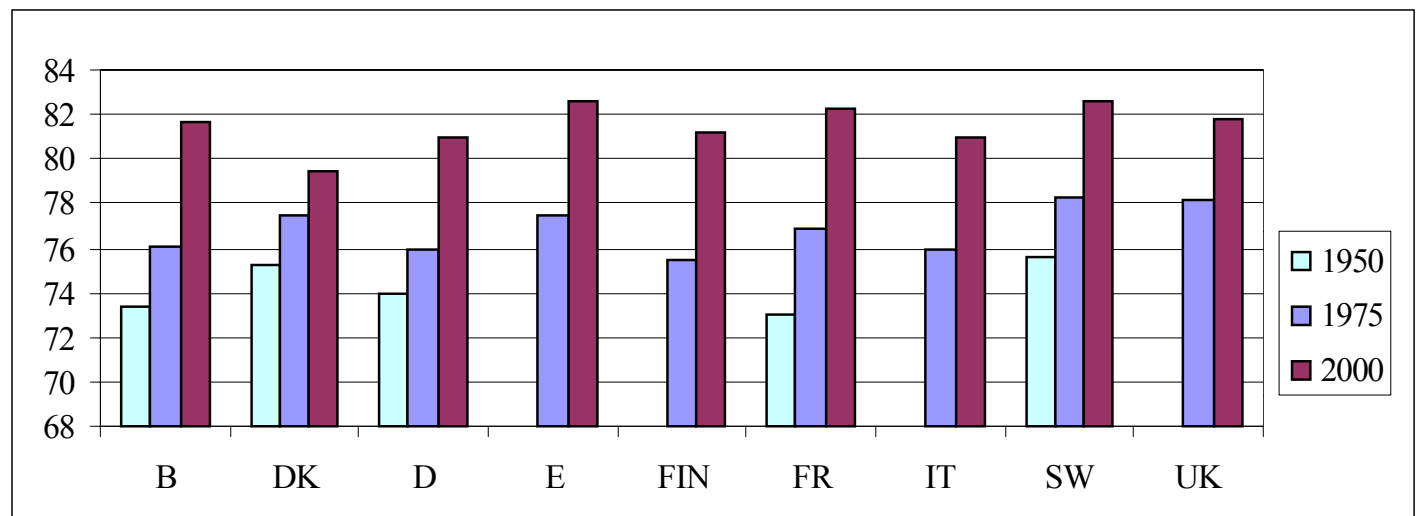

Source: Own computations based on data from national Statistical Offices completed with data from www.mortality.org.

Almost as marked seems to have been the evolution of a more demanding indicator of generational duration which is "life endurance" where the survival limit is 10 per cent of a given generation. The average age at which this limit is trespassed has risen from 87 years of age in 1950 to 89.5 in 1975 and again to 92.5 in 2000 on average for those countries where data has been available to the AGIR teams. A further indication of (mildly) accelerated compression at the high end of the survivors line. This can be seen in Figure 2.11, where the cases of Belgium and Germany, on the one hand, and Denmark, on the other, stand at the extremes whereas France (reckon the ages involved) clearly shows a considerable relative compression of its survival pattern.

Figure 2.11

Life endurance (age) 1950-1975-2000 for EU countries

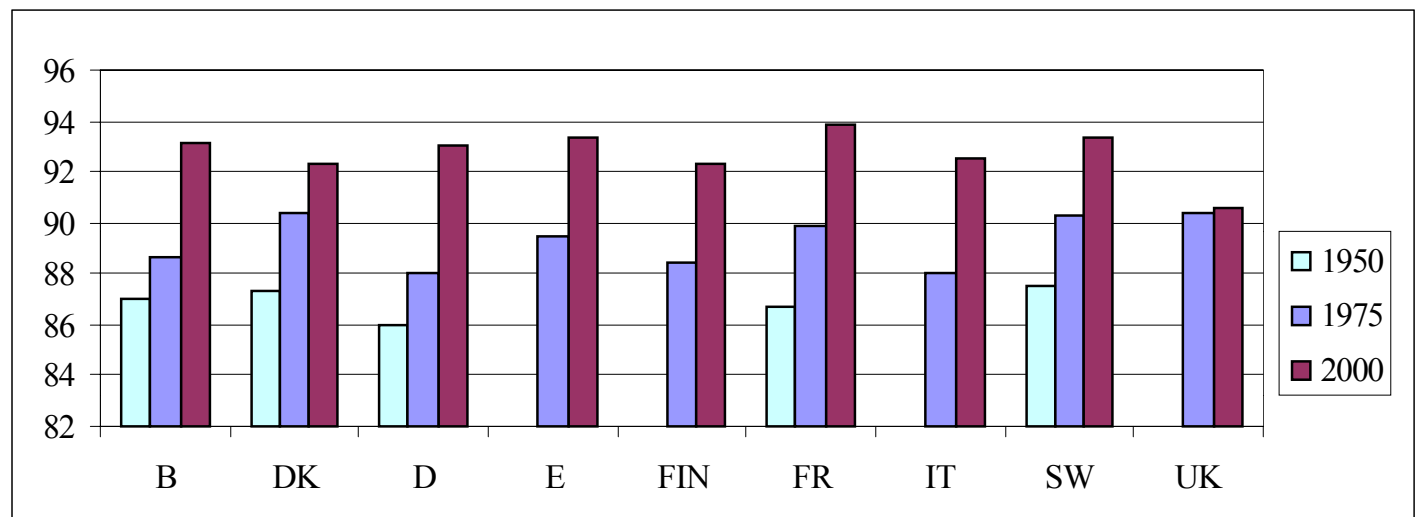

Source: Own computations based on data from national Statistical Offices completed with data from www.mortality.org. 
Also based on lifetables, the age at which most of the theoretical deaths (excluding infant deaths) happen in a given generation, so called "modal duration" has been steadily growing in the last decades. This can be seen in Figure 2.12 where the same pattern of acceleration could be observed but for few exceptions. It has to be said that this age can be very volatile as theoretical deaths are after all based on observed deaths whose numbers can be affected by many different circumstances. Nevertheless, modal duration stood near 78 years of age in 1950, rose to slightly above 80 in 1975 and lies close to 85 years in 2000.

Figure 2.12

Modal duration (age) 1950-1975-2000 for EU countries

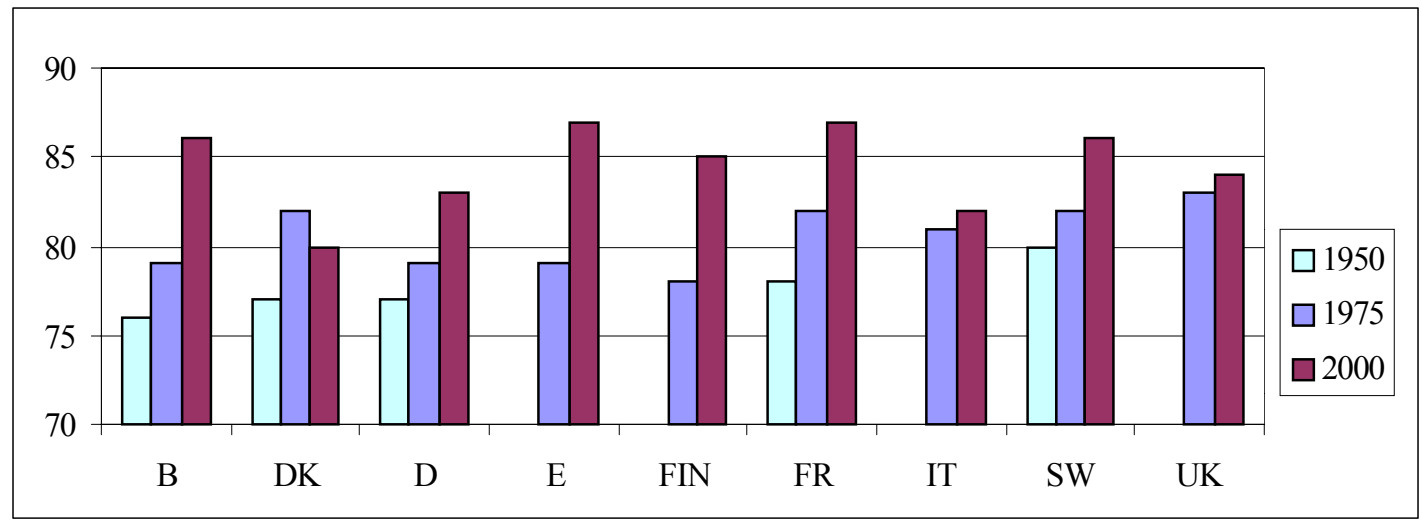

Source: Own computations based on data from national Statistical Offices completed with data from www.mortality.org.

Coming now to observed deaths, a suggestive indicator, albeit fraught with problems when it comes to actual value concerning average longevity, is the age of the oldest person dead in any year. This is called "record age" and, of course, varies enormously for only a handful of individuals, often just one, even in large countries, happen to reach that very extreme. Record ages for EU countries are shown in Figure 2.13 either for 1950-2000 or 1975-2000 and can be seen to have grown everywhere. France holds the record (in 1997) with Jeane Calment who died at 122. On average, record age has increased from 104 years in 1950 (roughly the same as in 1900) to 108 in 1975 and 110 in 2002. The later figure, however, is biased downwards by the fact that available death records in many countries collapse at age "110 or plus" thus biasing the whole average.

As said before, just a handful of individuals reach the highest age recorded at death in every country, but the number of "centenarians" is increasing rapidly year after year in every country. However, it would be simply wrong to infer from the above estimates of 
record ages that the limit age for a human being is actually increasing, let alone to provide the answer to the million euro question: ¿What is the limit age for a human life?

Figure 2.13

Record age 1950-1975-ca. 2000 for EU countries

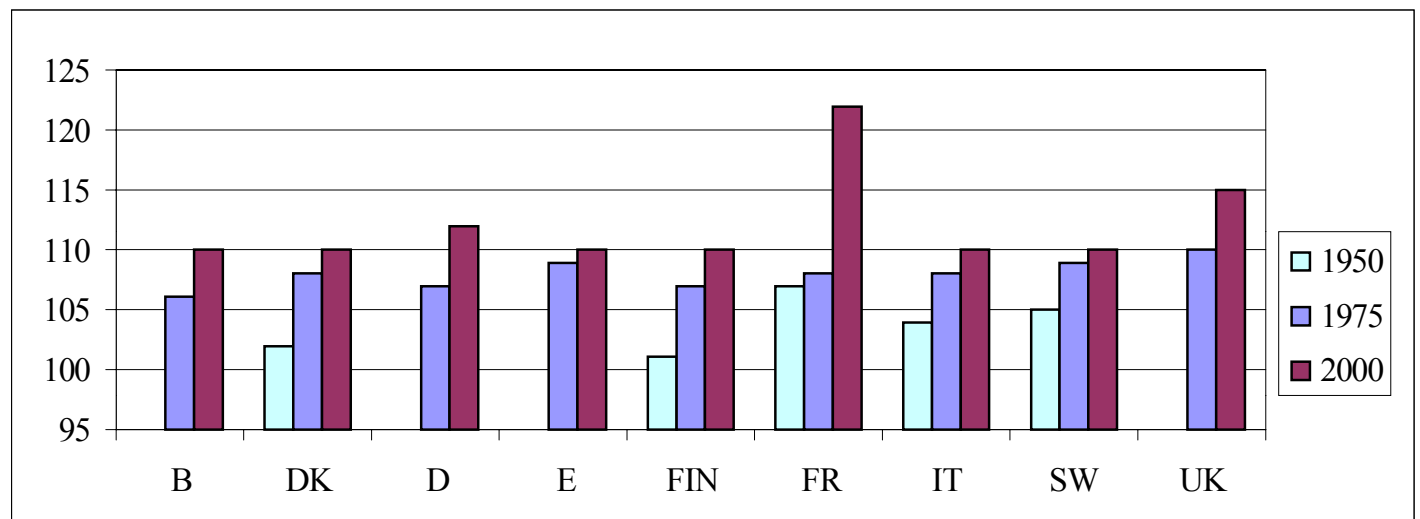

Source: Own computations based on data from national Statistical Offices completed with data from www.mortality.org.

All the previously discussed indicators of longevity can be put together as rough EU averages for the period 1975-2000, as done in Figure 2.14. All in all, only progress in longevity can be observed in the last fifty years in Europe. Indeed, while it seemed that the dramatic developments of the century prior to 1950 had left a marrow margin for improvements, gains have been happening nevertheless at an steady if not reinforced rhythm. 
Figure 2.14

Measuring longevity in the EU (averages) from 1950 to 2000

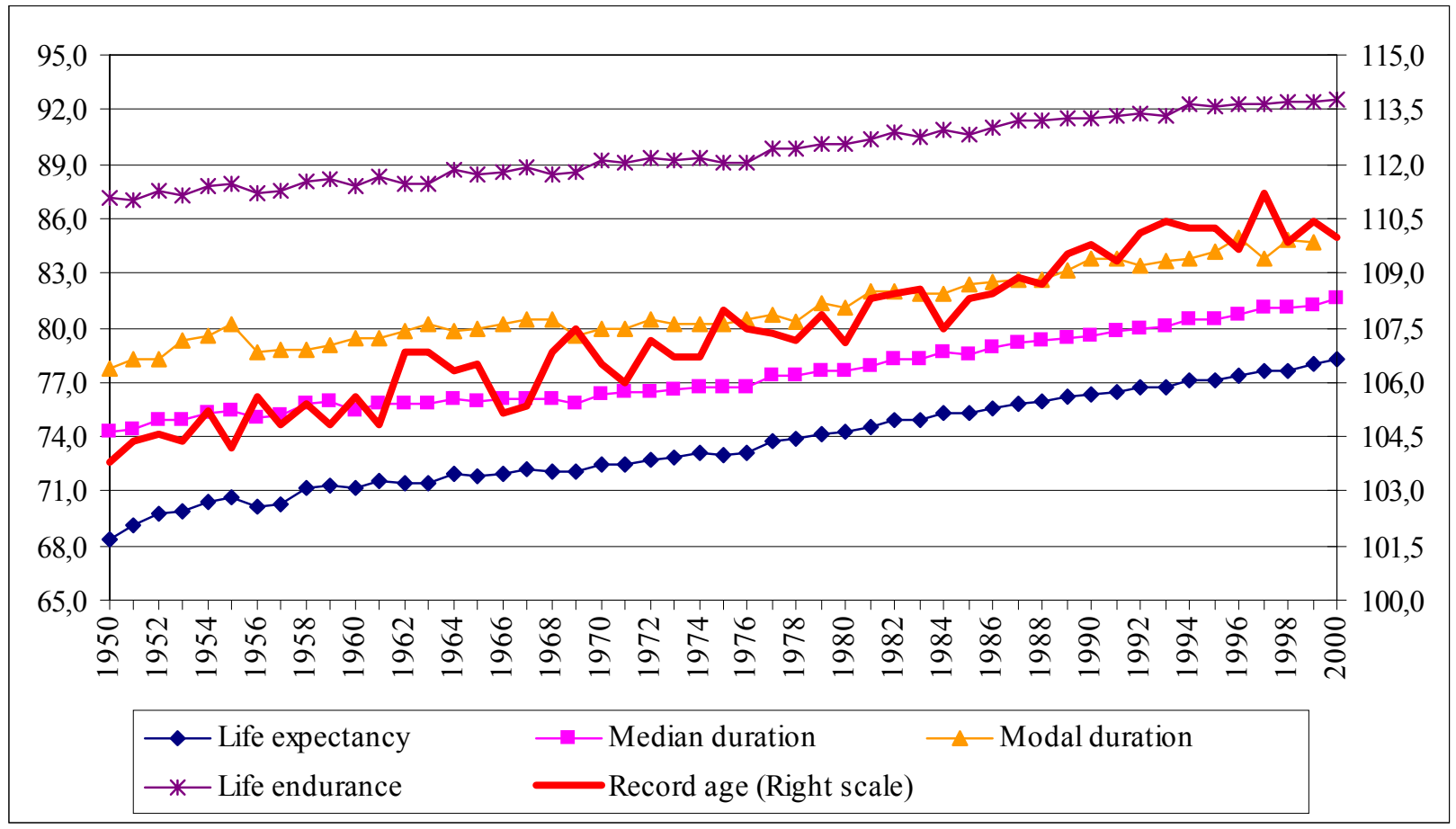

Source: Own computations based on data from national Statistical Offices completed with data from www.mortality.org.

\section{Lifecourses}

One of the aims of the team in charge of gathering demographic data within the AGIR project was to initiate the collection of data on what we have termed "lifecourses" that is those landmarks in a typical life cycle that mark the passage from one state to another, for instance, from school to the labour market, or from work to inactivity. One can think of quite a large set of such landmarks and we have chosen those shown in Figure 3.1. Given the fact that we were not able to collect data for all countries and all years, it is averages that are shown in the graph. These averages have been computed disregarding those observations likely to distort the resulting figure.

Also, it has to be taken into account that we are not talking about true cohorts when discussing about how different indicators relate to each other in any particular year. In fact, the figures discussed at a particular moment in time refer to strictly different generations. Those events happen to representative individuals of the concerned age that obviously do not belong to the same generation. If at all we could see the whole set of landmarks shown at any particular year as descriptive of a synthetic or theoretical generation. 
The story Figure 3.1 implies can be told as follows. Irrespective of gender, Europeans have been since mid last century leaving school at higher ages, finding their first job later and later, and thus leaving their parents home or getting married for the first time. They have, correspondingly, had their first babies also at higher and higher ages of the mothers (and fathers). So far, this means delayed entering into activity and household formation.

Once in the labour force and effectively working, what we know from many sources tells us that effective working periods have been far from been compact for many workers across Europe, due to unemployment although we have not gathered data to document this. Near retirement, invalidity and other pre-retirement events have increasingly prevented a significant share of the working force to continue working while retirement through old-age has shown a slightly declining trend around 60 years. Together with delayed entrance in the labour market, unemployment, pre-retirement through invalidity or workforce adjustments and declining old age retirement means increasingly reduced effective work spans for the average worker in the last decades.

After retirement, well below the age of 60 if we reckon with the various causes so far discussed that take workers definitely out of activity, individuals and household face a totally different life span. Widowhood intervenes typically several years after retirement, at younger ages for women than for men, and this event has had a dramatic development in just few decades. Around 1980 Europeans widowed at around the age of 65 while at present that age has increased to almost 70 years. On average also, life expectancy at 65 years (both genders) has increased from 10 more years in 1950 to 18 more years of life at present. 
Figure 3.1

"Lifecourses" in the EU - 1950 to 2000

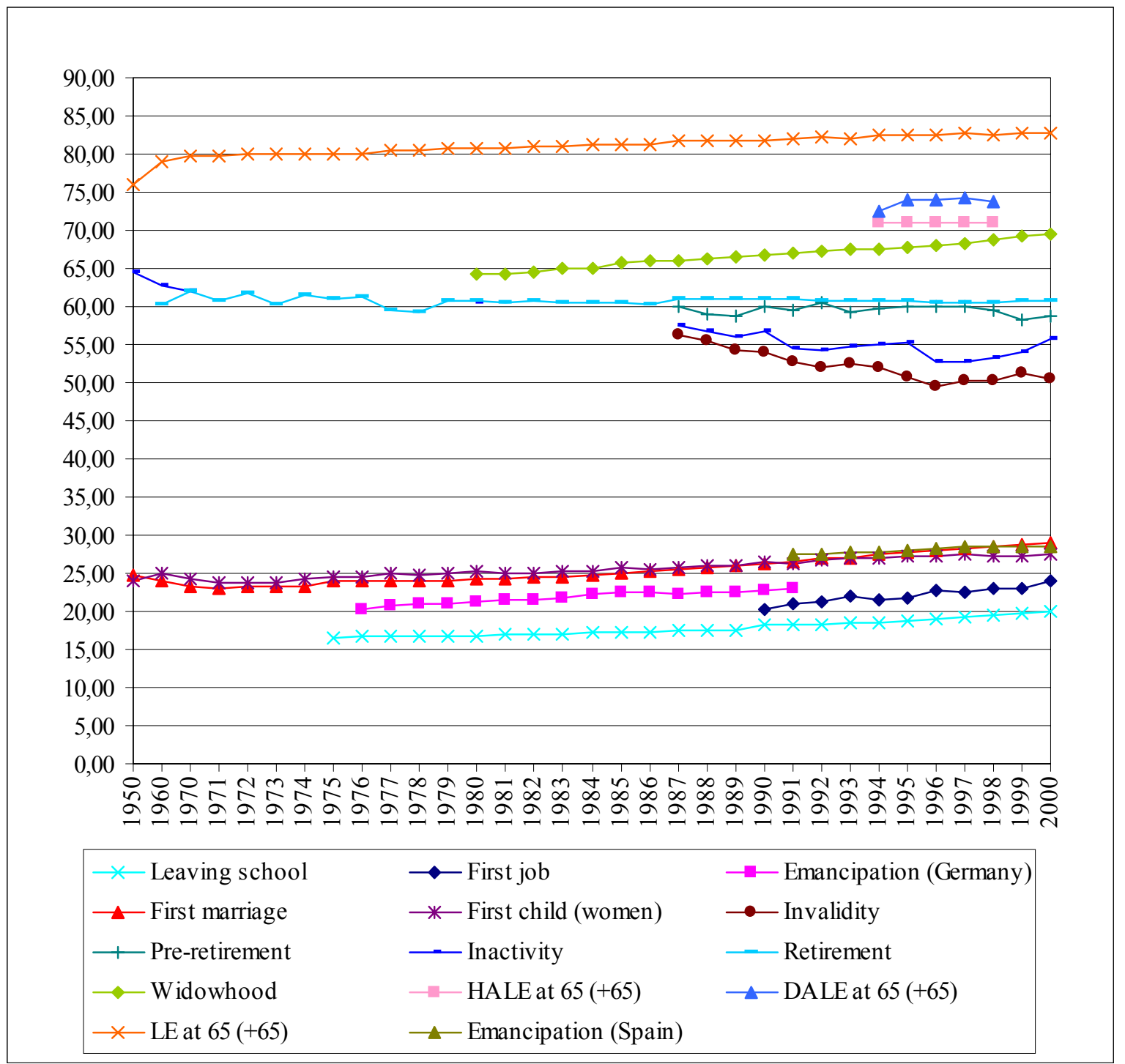

Source: Own computations based on data from national Statistical Offices and EUROSTAT, also completed with data from www.mortality.org.

However, that considerably enlarged post retirement span cannot be said to be free of troubles for roughly the second half of it will be marked by some sort of health ailment for the average individual as indicated by the "health adjusted life expectancies" or HALE indicators that we have computed out of the European Community Household Panel. Focusing on "disability adjusted life expectancy" or DALE, we find that, on average, even if these impairments would typically subtract less years to the total remaining life span after age 65 than general health troubles, the data available suggests an increased absolute morbidity due to disability. We explain below how these adjusted measures of remaining 
life years are however fraught with problems arising from the health and disability surveys themselves and other difficulties concerning their interpretation.

\section{Morbidity}

As life expectancy has increased substantially over decades, there is a natural interest in measuring life expectancy related to the health status of the population. A crucial question is that as we live longer, in what state of health do we live? Measuring health status of a population and comparing it with other populations has intrinsic interest as health is one of the most important factors which determine human well-being. Besides, health has important implications in broad areas of economics, from productivity, labor supply, health care costs and the sustainability of public health systems. In this section we compute and compare health status indicators and health adjusted life expectancies in European countries using survey data.

\subsection{Data}

One of the main harmonised data sources of self-assessed health status in Europe is the European Community Household Panel survey (ECHP) which started in 1994 across 12 European countries. Sampling and survey questions are carefully prepared to assure comparability across countries. A further advantage of the ECHP is that surveyed countries share more or less similar culture and development levels as well as geographical proximity. One of the questions included in the survey regarding health status is "How is your health in general?" with possible responses, "very good", "good", "fair", "bad" and "very bad". Other questions address chronic illness or disability, for instance: "Are you hampered in your daily activities by any chronic physical or mental health problem?" with possible responses, "yes, severely", "yes, to some extent", and "no". We analyze the responses to these two questions to compare health status and health-adjusted life expectancy across European countries. 
We examine only the first wave (1994) of the survey to avoid the problem of attrition. ${ }^{4}$ First, it is useful to check the internal consistency of self-assessed health status by examining the correlation between the two indices of health status that we will analyse. We expect a strong correlation between general health status and disability status: those who suffer from disability are likely to report worse health status. Indeed, as we can see in Table 4.1 below, there exists a strong correlation between the two variables. The proportion who suffer some degree of disability increases substantially as the declared health status worsens: the disability proportion decreases from $92 \%$ to $83 \%, 41 \%, 8 \%$ and to $3 \%$ as the declared health status moves from "very bad" to "bad", "fair", "good", and to "very good". When we examine each country, we find the same pattern without exception. This result is comforting as it provides some evidence for internal consistency at least at individual level.

\begin{tabular}{|c|c|c|c|c|c|c|}
\hline \multicolumn{7}{|c|}{$\begin{array}{c}\text { Table 4.1 } \\
\text { Proportion with disability and annual medical consultation by health status } \\
\text { ECHP 1994 }\end{array}$} \\
\hline & & \multicolumn{7}{c|}{ General Health Status } \\
\cline { 2 - 7 } & Very Bad & Bad & Fair & Good & Very Good & Total \\
\hline $\begin{array}{c}\text { \% with } \\
\text { Disability }\end{array}$ & 91.79 & 83.43 & 40.66 & 8.35 & 2.59 & 22.23 \\
\hline $\begin{array}{c}\text { \# annual medical } \\
\text { consultation }\end{array}$ & 8.54 & 7.55 & 5.28 & 3.14 & 2.34 & 3.91 \\
\hline \# Observation & 3166 & 9716 & 29,423 & 52,250 & 32,181 & 126,736 \\
\hline
\end{tabular}

Another check of internal consistency is performed by examining the correlation between health status and the use of health care services. Medical consultation frequencies increase significantly as individuals' health status worsen.

Another data source on health that we have available is national health surveys carried out in various countries more or less regularly. Some advantages of the data from national health surveys are that sometimes the sample size is large to provide precision in health estimates of the population as well as permitting a higher level of dis-aggregation of the data, that in some countries it is carried out regularly over time to allow us to examine possible trend in health status of the population, and that national health surveys usually

\footnotetext{
${ }^{4}$ Attrition problem is likely to be serious in the analysis of health status as health could be a cause of attrition. Indeed, among the respondents aged 65 and more in the first wave of the ECHP, the proportion missing in the second wave were $14.3 \%, 11,6 \%, 13.8 \%, 16.3 \%$ and $24.4 \%$ respectively corresponding to the first-wave reported health status 'very good', 'good', 'fair', 'bad' and 'very bad'.
} 
include a wide variety of information concerning health status, self-assessed as well as diagnosis based, the use of health care facilities, and health behaviour of the population. Although a series of national health surveys are available to us within the AGIR project we will not use those data in this paper. The results that follow would not be changed at all had we used these other data.

\subsection{General Health Status}

The general health status question is based entirely on respondents' own perception. The question asked is not concrete in terms of reference time period nor in the description of each category of health status, therefore leaving a large room for interpretation variability by interviewees. Second, the possible responses are ordered qualitatively. Comparing the responses between groups of people is not straightforward.

We begin with simple "averages" of the responses after assigning a cardinal value for each response ("very bad" $=0$, "bad" $=1, \ldots$, "very good" $=4$ ). The simple average provides a health index (the bigger the average, the better health) which is comparable across the populations if we are willing to assume the linearity across responses. The "average" health status by 5 years age interval for 11 European countries is presented in Figure 4.1. Luxembourg is excluded for its small sample size.

Figure 4.1

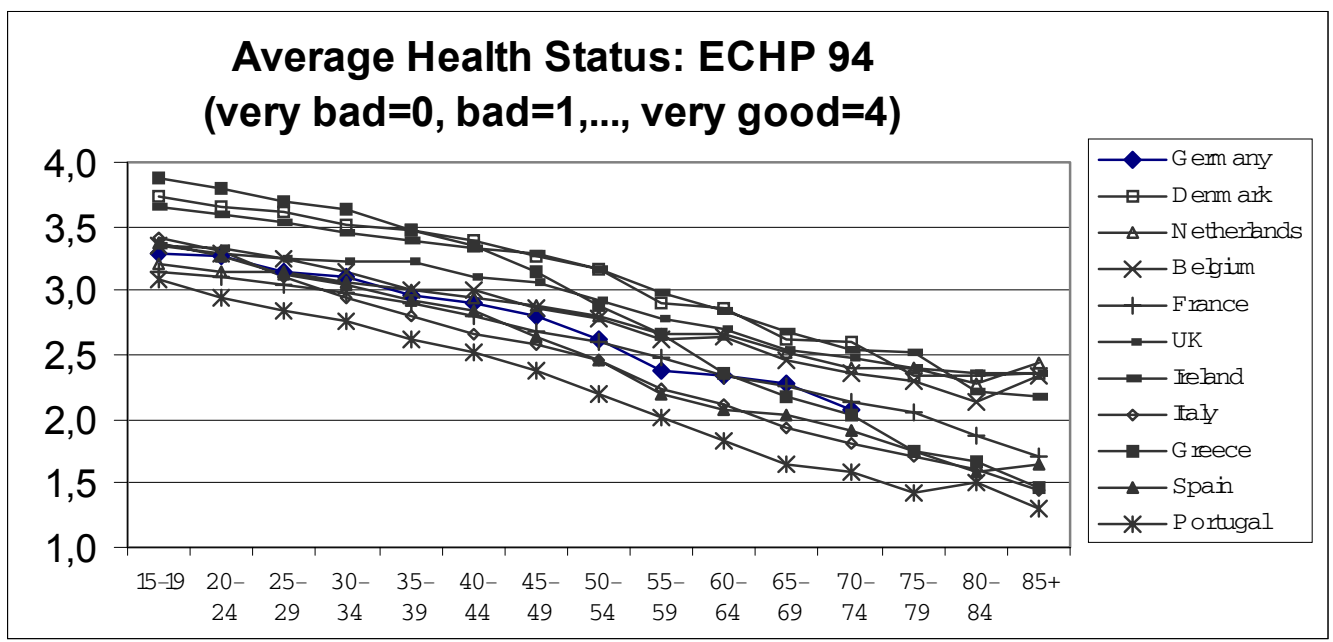

The first impression we receive from the figure is that self-assessed health status gets worse with age by a similar gradient across countries. More importantly, there are large differences in health status for given ages between the countries. For most age 
groups, Denmark and Ireland report best health status while Portugal, Italy and Spain report worst health status. Peculiarly, Greece report best health among the young (less than 40) population but relatively worse health among the elderly (over 70) population. The differences between countries are surprisingly large and the ranking is not completely convincing as judged by other health measures, such as life expectancy. ${ }^{5}$

Given that the comparison of "average" health status analysed above is valid only in the case that the response categories can be assigned with linearly aligned values, the index loses substantive meaning in general. For the comparisons which suffer less of this arbitrary assignment of values, we compare the proportions who report good or very good health status as well as the proportions with bad or very bad health status.

Figure 4.2

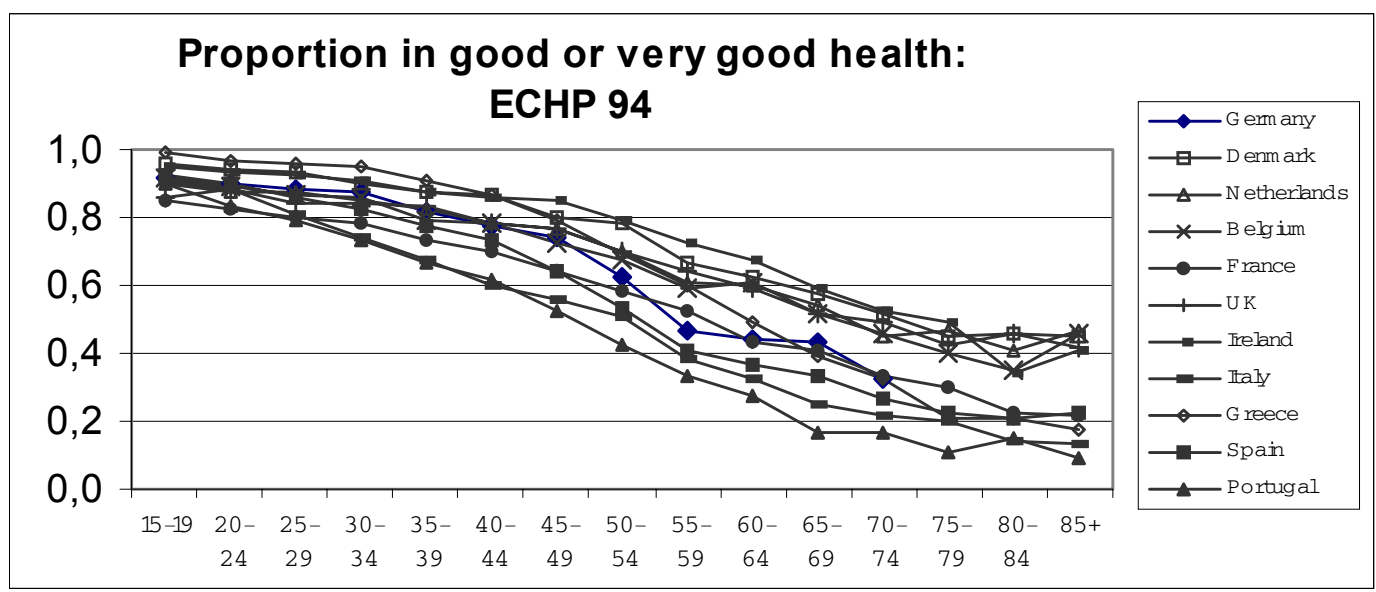

Figure 4.3

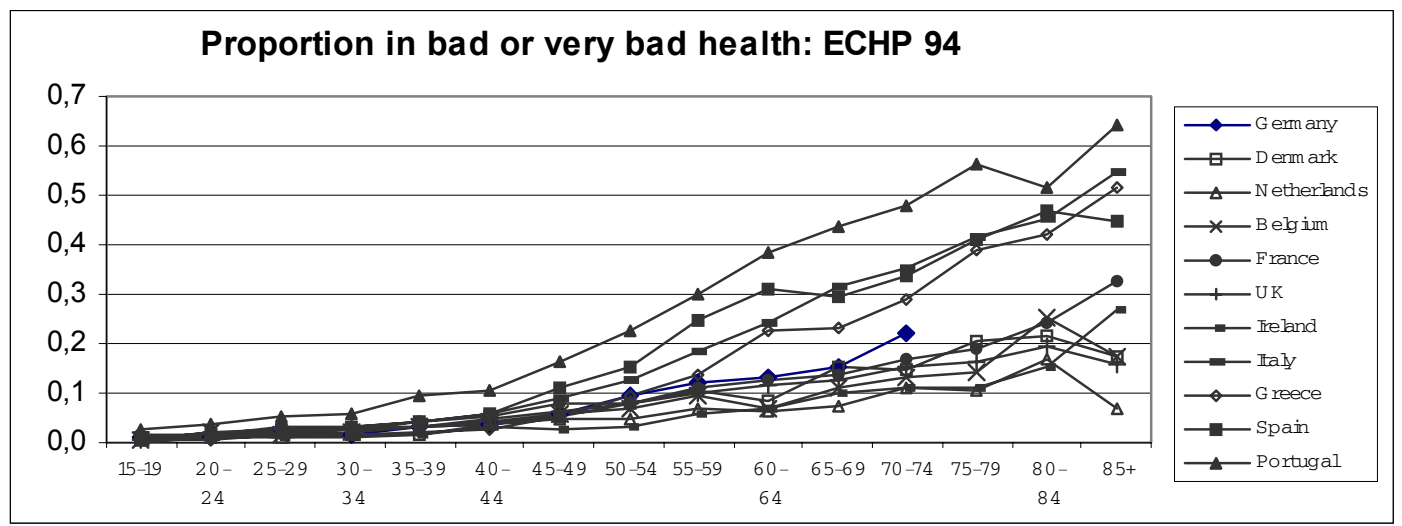

\footnotetext{
${ }^{5}$ According to WHO (2000), life expectancy at birth is longest in France, Italy and Spain and shortest in Ireland, Portugal and Denmark with the differences of about 2.5 years between the two groups.
} 
In the case of good or very good health, the proportion varies substantially between countries even among the young population and the difference widens with age. The crosscountry differences are too large to accept as genuine differences. For example, the proportion in good health among the population aged 65-69 is less than $20 \%$ in Portugal while it is close to $60 \%$ in Ireland and Denmark. In the case of bad or very bad health, the differences across countries are even larger among the middle and old age population. For example, Ireland and The Netherlands have the proportion in bad or very bad health at lower than $10 \%$ among the population aged $65-69$, while the corresponding proportion is higher than $30 \%$ in Portugal, Spain and Italy.

\subsection{Disability Status}

The second question we analyse is disability status. In principle, we think that disability status would suffer less from the cultural or social environment bias, as the question is more concrete and less subjective. Given that the response categories are "none", "to some extent" and "severely", we consider the proportion with severe or moderate disability as well as that with only severe disability.

Figure 4.4

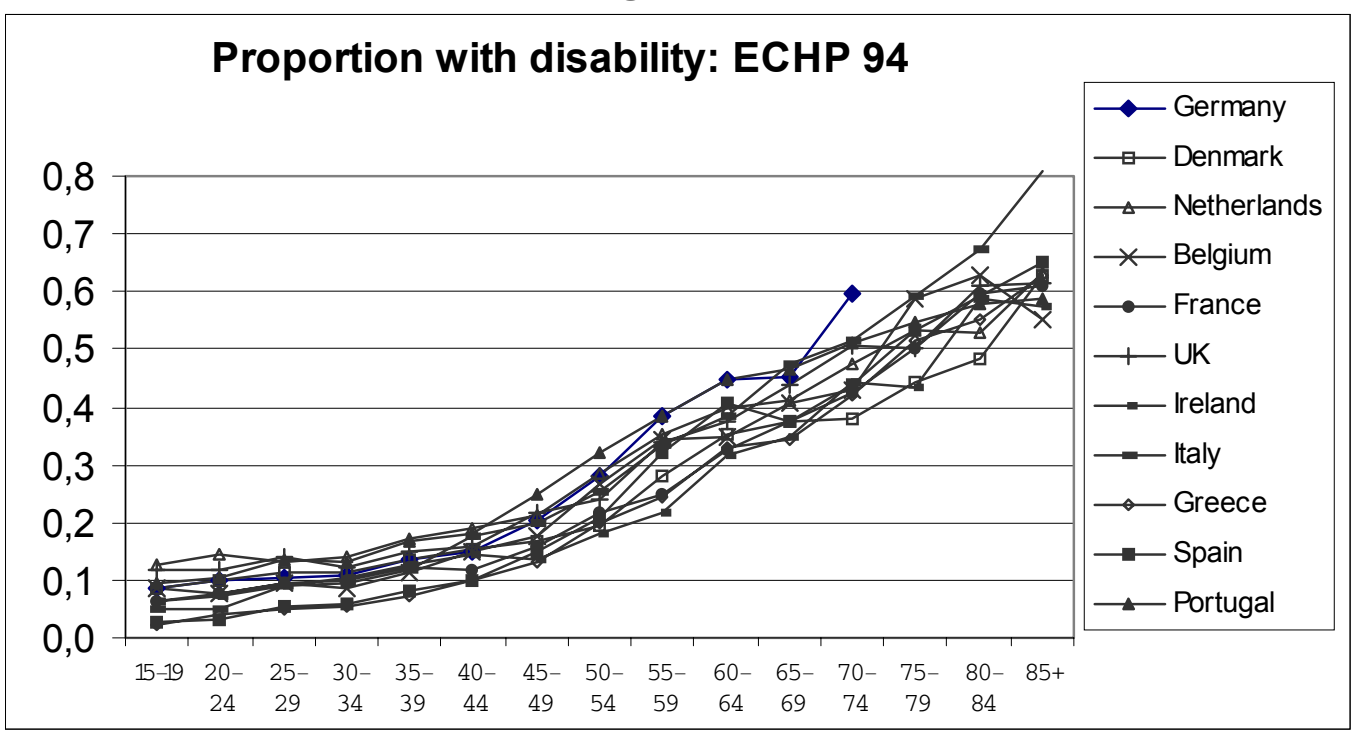


Figure 4.5

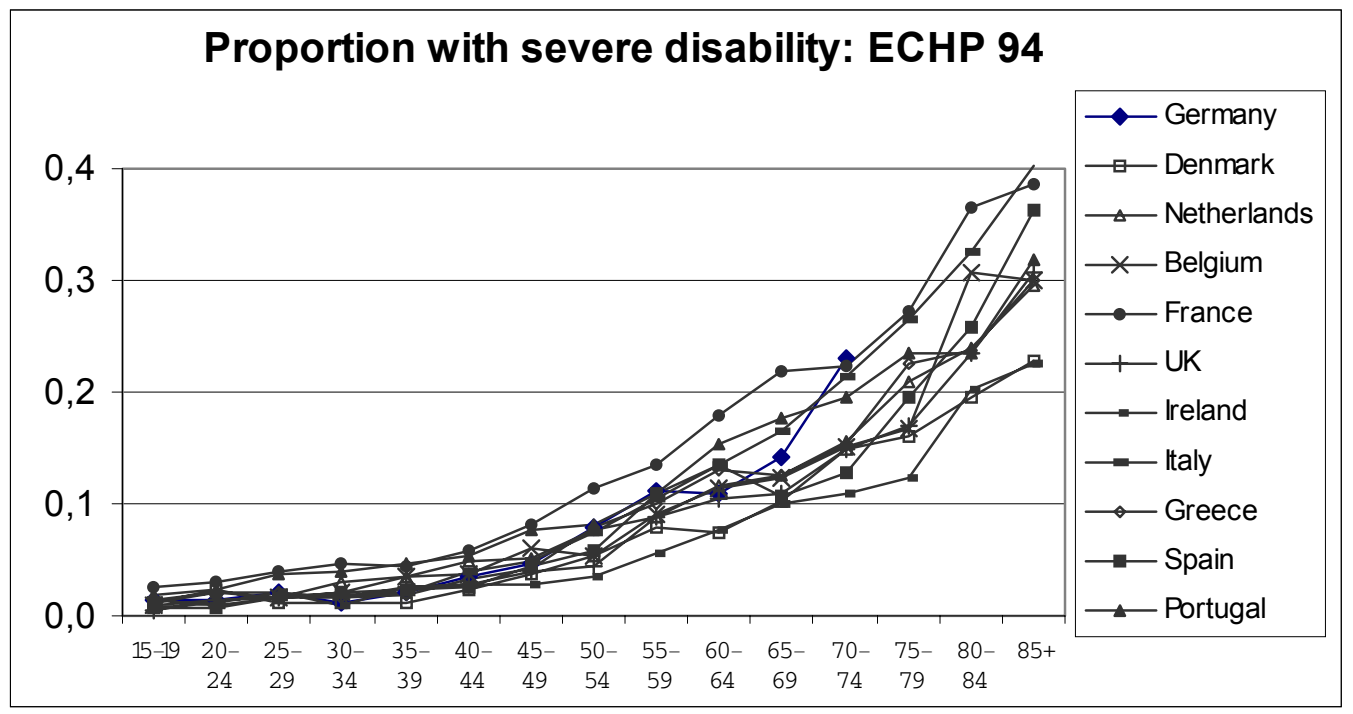

The age profile of disability is as expected: older people suffer more often from disability. Cross-country differences are somewhat smaller than in the case of general health status. Nevertheless, the differences between countries are again substantial enough to lead us to be reluctant in accepting them as genuine differences across countries. For example, the proportion with some disability among the population aged 16-24 is less than 5 percent in Spain and Greece while it is higher than 12 percent in The Netherlands. Among the population aged 55-59, as another example, the disability rate is less than $25 \%$ in Ireland and Greece while it is almost $40 \%$ in Germany and Portugal. If we examine the proportion with severe disability, the cross-country differences are proportionally larger, especially among the elderly population. Here, France stands out for its high prevalence of severe disability. For example, at ages 65 to 69 , the severe disability rate is $22 \%$ in France while that in UK, Ireland and Spain is only $10 \%$. Moreover, the country ranking of disability rate is widely different from that of general health status. A part of cross-country differences at old ages may be due to the differences in the proportion of institutionalised population which is not included in the ECHP.

One potential factor which might contribute to cross-country differences in the perception of health status is the time (month) of year when the survey is carried out. Indeed, there were considerable variations between countries in the month of year when the surveys are carried out. It is possible that people enjoy different health status according to the season due to seasonal variation of physical exercise. Mental health and mood may also vary according to the season. To explore this possibility, we estimated individual health 
status (ordered logit regression for health status and logit regression for disability status) including month and country dummies. The results indicate that month dummies are in general not significant, therefore not a factor which can explain the observed cross-country differences in self-assessed health status.

In summary, self-assessed general health status and disability status vary widely across European countries. The differences are so large and often the country rankings change across different measures or do not coincide with other health measures (such as life expectancy) that we have to be careful in the interpretation of the cross-country differences (Ahn, 2002).

\subsection{Health and education in the EU}

Many studies have found a positive association between health and socioeconomic status (income, wealth, education and occupation level, and employment status). However, the direction of causation between them is difficult to establish, and is most likely that it runs both way (see Bound, 1991; Dwyer and Mitchell, 1999 and the survey by Smith, 1999). For example, those with better health are likely to be more productive and enjoy therefore greater earning potentials. On the other hand, greater wealth allows easier access to and better quality of health care therefore providing better health outcome. It is also possible that there are unobserved factors which affect both wealth and health in a same direction, thus leading to the observed positive relation between the two. For example, those who are far sighted are likely to take more care of their health and therefore more productive and also save more, therefore leading to the observed positive association.

Education level suffers less from endogeneity problems than other socioeconomic variables since most people complete their schooling relatively early (before age 25) when their health status is in most cases good enough not to interfere with their schooling. For example, as we could observe earlier, the proportion with bad or very bad health among those aged less than 35 is less than $5 \%$ in all the ECHP countries. Many studies have shown education as a single most important socioeconomic characteristics in determining various measures of health (for example, Elo and Preston, 1996, in mortality and Freedman and Martin, 1999, in function limitations). 


\section{Education on General Health Status}

We first examine the effect of education on general health status. In the following Table 4.2 we present regression results of health status for the 11 European countries in ECHP. Three schooling levels are distinguished, low (omitted category), medium and high.

\begin{tabular}{|l|c|c|c|c|c|c|}
\hline \multicolumn{7}{|c|}{$\begin{array}{c}\text { Table 4.2 } \\
\text { (orfect of Education Level (relative to low education level) on Health Status } \\
\text { (orded logit coefficients in parenthesis are not significant at 5\% level) }\end{array}$} \\
\cline { 2 - 7 } & \multicolumn{2}{|c|}{ Ages 25-44 } & \multicolumn{2}{c|}{ Ages 45-64 } & \multicolumn{2}{c|}{ Ages 65+ } \\
\hline & Medium & High & Medium & High & Medium & High \\
\hline Germany & 0.176 & 0.508 & 0.292 & 0.757 & 0.385 & 0.421 \\
\hline Denmark & 0.551 & 0.903 & 0.769 & 0.988 & 0.258 & 0.553 \\
\hline Netherlands & 0.299 & 0.708 & 0.402 & 0.669 & 0.391 & 0.638 \\
\hline Belgium & 0.269 & 0.644 & 0.371 & 0.600 & $(0.363)$ & 0.618 \\
\hline France & 0.304 & 0.405 & 0.355 & 0.613 & 0.322 & 0.588 \\
\hline UK & 0.322 & 0.778 & 0.473 & 0.869 & 0.449 & 0.754 \\
\hline Ireland & 0.675 & 0.904 & 0.485 & 0.991 & 0.759 & 1.145 \\
\hline Italy & 0.342 & 0.672 & 0.444 & 0.610 & 0.548 & 1.008 \\
\hline Greece & 0.172 & 0.300 & 0.597 & 0.832 & 0.433 & 1.062 \\
\hline Spain & 0.365 & 0.599 & 0.824 & 1.145 & 1.038 & 0.817 \\
\hline Portugal & 0.701 & 1.055 & 1.209 & 0.969 & 1.282 & 0.998 \\
\hline
\end{tabular}

The results are encouraging. Among the 66 estimated coefficients, only one (medium education level for ages $65+$ in Belgium) is not significant at 5\% level. We can see persistently substantial effects of education on self-assessed health status across countries and for all age groups, suggesting that there exist a genuine beneficial effects of education in health. This hypothesis is supported by the fact that even when we include other socioeconomic variables, such as employment status and household income, the education coefficients maintain almost entirely their magnitude and statistical significance.

\section{Education on Disability}

Education again stands out as an important factor in determining the probability of disability across countries and in all age groups. In most cases, education lowers substantially the probability of suffering disability. This difference by education level is greater among younger people than those over 64 years. Among those 65 or older, only those with high education level enjoy significantly lower rates of disability, and this effect of high education is greater among the Southern European countries than other countries (Table 4.3). 


\begin{tabular}{|l|c|c|c|c|c|c|}
\hline \multicolumn{7}{|c|}{$\begin{array}{l}\text { Table 4.3 } \\
\text { Effect of Education Level (omitted: low) on Disability Status } \\
\text { (logit coefficients in parenthesis are not significant at 5\% level) }\end{array}$} \\
\cline { 2 - 7 } & \multicolumn{2}{|c|}{$25-44$} & \multicolumn{2}{c|}{ 45-64 } & \multicolumn{2}{c|}{$65+$} \\
\hline \multirow{2}{*}{ Medium } & High & Medium & High & Medium & High \\
\hline Dermany & $(0.045)$ & -0.366 & $(-0.083)$ & -0.447 & $(-0.101)$ & $(-0.142)$ \\
\hline Netherlands & -0.848 & -1.014 & -0.675 & -0.896 & $(-0.150)$ & $(-0.281)$ \\
\hline Belgium & -0.281 & -0.640 & -0.341 & -0.693 & $(-0.102)$ & $(-0.259)$ \\
\hline France & -0.272 & -0.952 & -0.379 & -0.386 & $(-0.193)$ & -0.386 \\
\hline UK & -0.374 & -0.900 & -0.324 & -1.169 & -0.250 & -0.512 \\
\hline Ireland & -0.223 & -0.607 & -0.279 & -0.542 & $(-0.145)$ & -0.345 \\
\hline Italy & -0.824 & -1.082 & -0.632 & -1.198 & $(-0.154)$ & -0.933 \\
\hline Greece & -0.390 & -0.992 & -0.629 & -0.835 & -0.285 & -0.870 \\
\hline Spain & -0.453 & -0.518 & -0.586 & -0.996 & $(-0.187)$ & -1.028 \\
\hline Portugal & -0.676 & -1.222 & -0.791 & -1.441 & -0.800 & -0.677 \\
\hline
\end{tabular}

Educational composition to explain cross-country health status differences

Given the persistent effect of education level on individual health status for all countries analyzed, we may ask "Is it the differences in educational composition which explain cross-country differences in health status?" Indeed, education level shows substantial differences between the countries across the age groups. For example, the proportion with the high level of education is close to $40 \%$ in Belgium and Denmark while it is less than or close to $10 \%$ in Portugal and Italy among those aged 25 to 44 . Similar differences exist for other age groups as seen on Table 4.4

Table 4.4

Educational Composition : ECHP 94

\begin{tabular}{|l|c|c|c|c|c|c|}
\hline & \multicolumn{2}{|c|}{ Ages 25-44 } & \multicolumn{2}{c|}{ Ages 45-64 } & \multicolumn{2}{c|}{ Ages 65+ } \\
\cline { 2 - 7 } & \% medium & \% high & \% medium & \% high & \% medium & \% high \\
\hline Belgium & 34.98 & 39.14 & 27.49 & 26.65 & 22.57 & 13.42 \\
\hline Denmark & 40.88 & 39.11 & 35.06 & 31.21 & 24.09 & 14.40 \\
\hline France & 46.21 & 24.30 & 31.50 & 15.67 & 15.27 & 7.00 \\
\hline Germany & 55.31 & 23.49 & 46.55 & 21.52 & 38.21 & 14.30 \\
\hline Greece & 31.40 & 28.12 & 15.24 & 11.21 & 9.03 & 4.16 \\
\hline Ireland & 42.40 & 16.63 & 27.36 & 10.80 & 12.89 & 5.63 \\
\hline Italy & 42.63 & 10.12 & 20.78 & 6.34 & 13.17 & 3.80 \\
\hline Netherlands & 63.10 & 21.39 & 56.58 & 18.07 & 43.61 & 9.91 \\
\hline Portugal & 12.69 & 6.62 & 3.17 & 3.43 & 1.41 & 1.17 \\
\hline Spain & 20.20 & 24.81 & 6.92 & 9.18 & 3.88 & 3.94 \\
\hline UK & 38.61 & 26.11 & 27.85 & 19.98 & 18.49 & 10.72 \\
\hline
\end{tabular}


To contrast the hypothesis, we examine the health status by education level for three age groups as defined earlier as shown in the following Figure 4.6a to 4.6c. If the individuals in the same education category but in different countries show similar levels of health status, cross-country health status differences could be attributed to the compositional differences in education.

Figure 4.6a

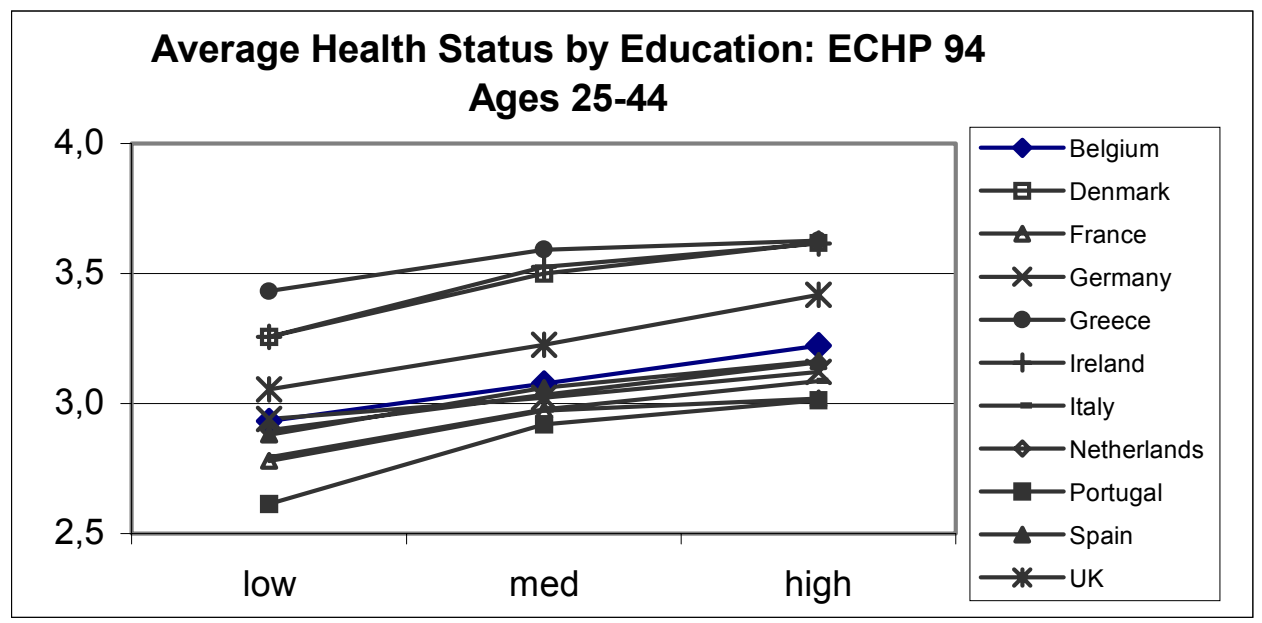

Figure 4.6b

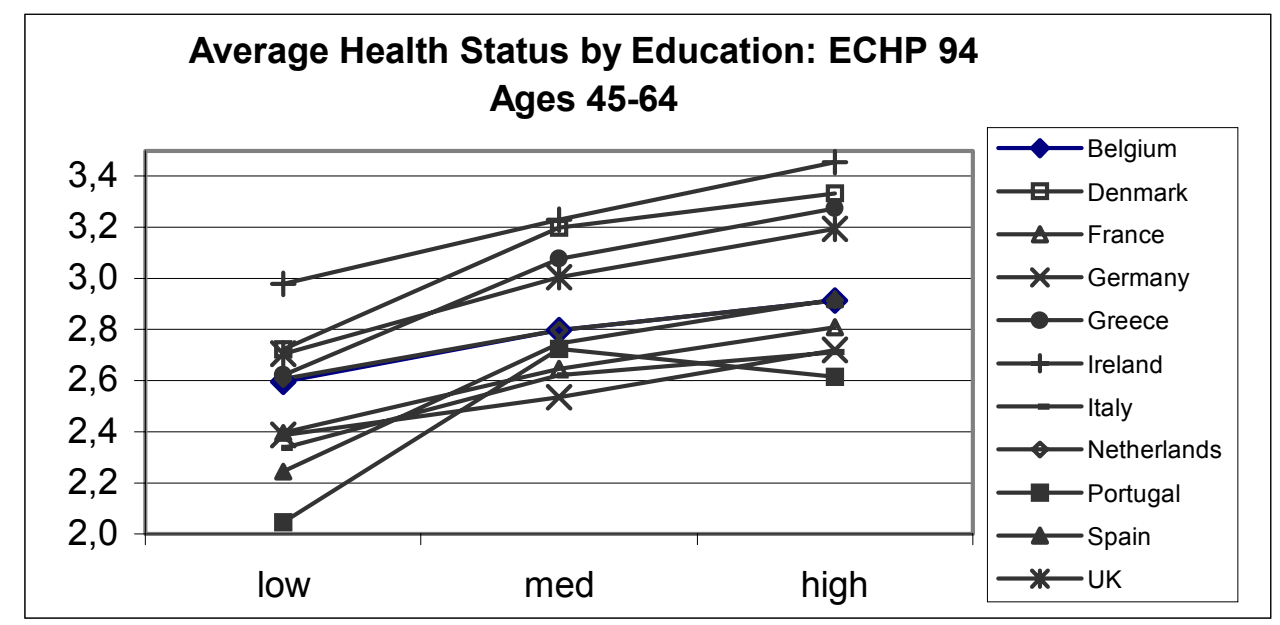


Figure 4.6c

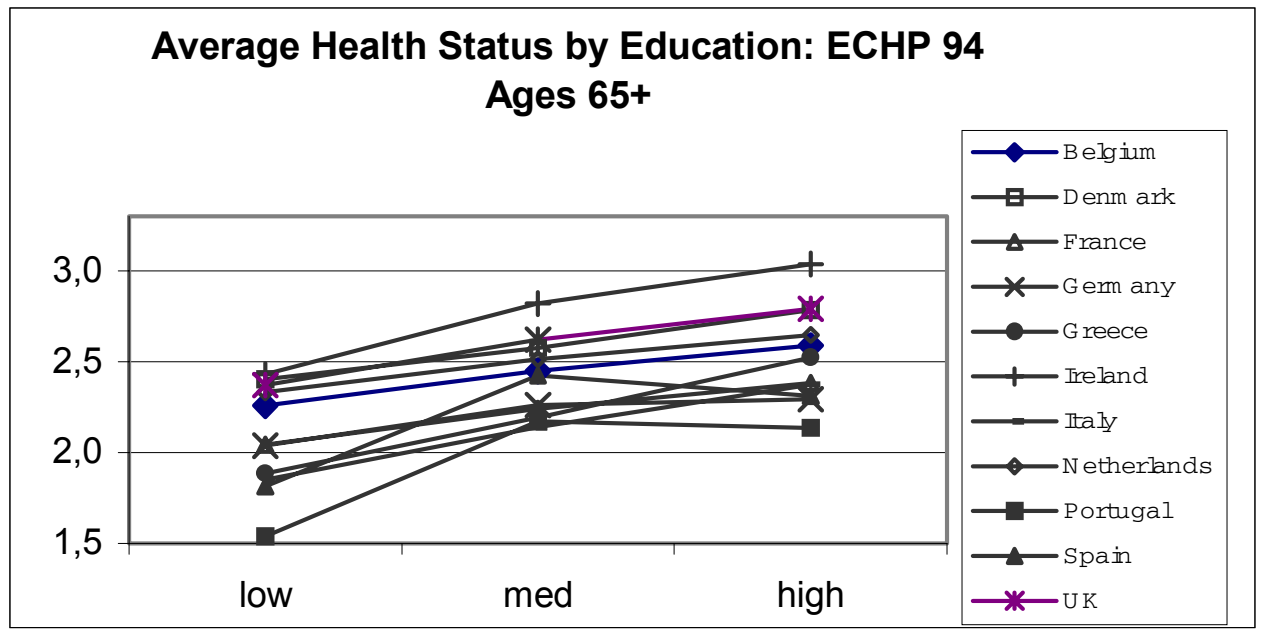

The hypothesis can be rejected clearly. Education level affects significantly individual health status in all countries as shown in the positive slope. However, education profiles of health status are parallel between countries for most countries. Cross-country health status variations at each level of education are much greater than the variations by education within each country. Therefore, the differences in health status between countries are attributed more to the country specific effects than to the educational composition.

\section{Health adjusted life expectancies. Trends and future scenarios.}

\subsection{Concept and illustrations}

\section{What are Health Expectancies?}

Health expectancies are summary measures of population health which refer to the mean time (in years) that a person of given age can expect to live in a specific health state. Health expectancy is a generic term used for any life expectancy lived in a specific health state, which includes good health (i.e. disability free) or poor health (i.e. disabled).

Since the late eighties, an international group called "REVES" headed by J-M Robine has developed and promoted the concepts and methodology for the calculation of these indicators which are currently widely calculated and used by different countries for the evaluation of population health status (Mathers et al., 1993). In a wider perspective, the 
World Health Organisation has published in recent years different indicators of health expectancies (WHO, 2000; WHO, 2001 and WHO, 2002) for all member States.

When using health expectancies, the years lived are not equally considered independently of the health state as it occurs when calculating life expectancy, but the distinction is made between years lived in perfect health and years lived with some type of health problem. Health expectancy indicators thus constitute an attractive instrument for the long term follow-up of population health tendencies. They can be easily interpreted as an extension of the life expectancy concept.

However, for them to be really useful, these indicators must be comparable among populations and through time. This means, on one hand, to use homogenous concepts and definitions of health and, on the other hand, to use comparable tools to obtain the information about the population health status. Finally, several methods to calculate health expectancies have been developed. A key issue in health expectancy calculation is the need to define what is understood by health, in other words, under what criteria the health status of a population is established. For all these reasons, it is not a surprise that there are as many possible health expectancy measures as health concepts and methods to calculate them (Robine et al., 1999).

\section{Computing Health Expectancies}

The most frequently used method for calculating health expectancy measures is Sullivan's method. It uses disability prevalence data or population health status data to distinguish between hypothetical years of life lived with or without disability for a fictitious cohort derived from a period mortality table. The main limitations of this methodology are: Comparability between populations (can only be partially achieved using common standardized models of protocols and questionnaires); the lack of information about the transition or reversibility of different health states or disabilities; and that they offer stock information, that is, accumulated results of the consequences of incidence of diseases and injuries which did not necessarily occur at the same year that the survey took place.

The main advantages of Sullivan's method lie in the simplicity of the calculations and the relative easiness to obtain required information: it only requires a mortality table and health state prevalence of the population which can be obtained easily from health or 
disability surveys. In some cases, data can even be obtained from some census questionnaires.

\section{Health Expectancies using the ECHP}

As mentioned before, there is one statistical source common for all EU countries. The European Community Household Panel (ECHP) is a survey (conducted yearly since 1994) based on a standardised questionnaire that involves annual interviewing of a representative panel of households and individuals in each country, covering a wide range of topics. Main questions regarding health and disability in ECPH are related to self perceived health and to disability. Although the questionnaire (questions and scale of responses) is virtually the same in all countries, it became apparent from these surveys that standardised instruments did not solve the problems of comparability across countries. These problems relate much more fundamentally to unmeasured differences in expectations and norms for health. Mathers (2003) and Sadana et al (2002) also highlight this problem. After calculating Disability-Free Life expectancies (DFLE) in the UE countries (1994 wave, 12 countries) with the Sullivan method and life tables supplied by Eurostat, Robine et al. (2001) evaluate the advantages of this source, but also point out some problems such as different versions of questionnaire, different rate of response and the exclusion of institutionalised population in the sample.

Based on the ECHP we have computed, following Sullivan's method, a series of illustrative disability adjusted life expectancy measures that are shown in Table 5.1 where DFLE stands for Disability Free Life Expectancy, DLEm stands for Life Expectancy lived in moderate disability and DLEs stands for Life Expectancy lived in severe disability. 
Table 5.1

Life Expectancy at birth and at age 65 Free of Disability, with Moderate Disability and with Severe Disability European Union. Year 1994. Both Sexes

\begin{tabular}{lrrrr} 
At birth & \multicolumn{1}{c}{ Women } & \multicolumn{3}{c}{ L } \\
& DFLE & DLEm & \multicolumn{1}{c}{ DLEs } & L \\
France & 64,6 & 8,2 & 9,1 & 81,9 \\
Spain & 63,5 & 12,0 & 5,9 & 81,4 \\
Italy & 61,1 & 13,0 & 6,9 & 81,0 \\
The Netherlands & 58,9 & 15,3 & 6,2 & 80,3 \\
Greece & 65,0 & 9,5 & 5,7 & 80,2 \\
Belgium & 61,4 & 12,9 & 5,8 & 80,1 \\
Luxembourg & 60,9 & 15,5 & 3,3 & 79,7 \\
Germany & 60,0 & 14,1 & 5,5 & 79,6 \\
United Kingdom & 60,8 & 13,8 & 4,7 & 79,3 \\
Ireland & 64,0 & 11,7 & 2,9 & 78,6 \\
Portugal & 56,7 & 15,1 & 6,8 & 78,6 \\
Denmark & 61,3 & 12,6 & 4,2 & 78,1
\end{tabular}

At birth
Greece
Italy
The Netherlands
Spain
United Kingdom
France
Belgium
Luxembourg
Germany
Ireland
Denmark
Portugal

\begin{tabular}{crrr} 
Men & \multicolumn{3}{l}{} \\
DFLE & \multicolumn{1}{l}{ DLEm } & \multicolumn{1}{c}{ DLEs } & LE \\
63,0 & 7,5 & 4,7 & 75,2 \\
60,4 & 9,5 & 4,6 & 74,6 \\
59,0 & 11,1 & 4,5 & 74,6 \\
61,8 & 8,2 & 4,2 & 74,2 \\
59,1 & 11,5 & 3,6 & 74,1 \\
60,1 & 6,7 & 6,9 & 73,8 \\
60,3 & 9,0 & 4,1 & 73,4 \\
59,2 & 10,9 & 3,1 & 73,2 \\
56,7 & 11,5 & 5,0 & 73,1 \\
61,2 & 9,2 & 2,6 & 73,0 \\
60,7 & 8,9 & 3,1 & 72,7 \\
55,0 & 11,0 & 5,6 & 71,6
\end{tabular}

\begin{tabular}{|c|c|c|c|}
\hline Age 65 & $\begin{array}{l}\text { Women } \\
\text { DFLE }\end{array}$ & DLEm & DLEs \\
\hline France & 10,3 & 4,4 & 5,9 \\
\hline Spain & 9,1 & 6,4 & 4,3 \\
\hline Italy & 7,7 & 6,7 & 5,0 \\
\hline Belgium & 9,2 & 6,1 & 3,8 \\
\hline The Netherlands & 8,6 & 6,5 & 4,0 \\
\hline Luxembourg & 10,4 & 6,6 & 1,7 \\
\hline Germany & 7,9 & 6,6 & 3,9 \\
\hline Greece & 9,7 & 5,1 & 3,6 \\
\hline United Kingdom & 8,5 & 6,4 & 3,4 \\
\hline Portugal & 7,9 & 6,1 & 3,9 \\
\hline Denmark & 9,2 & 5,6 & 2,9 \\
\hline Ireland & 9,8 & 6,0 & 1,5 \\
\hline
\end{tabular}

$\quad$ Age 65
France
Greece
Spain
Italy
Belgium
The Netherlands
Germany
Luxembourg
United Kingdom
Portugal
Denmark
Ireland

\begin{tabular}{|c|c|c|c|}
\hline \multicolumn{4}{|l|}{ Men } \\
\hline DFLE & DLEm & DLEs & LE \\
\hline 8,9 & 3,0 & 4,3 & 16,2 \\
\hline 8,7 & 4,4 & 3,1 & 16,1 \\
\hline 9,0 & 4,7 & 2,3 & 16,0 \\
\hline 7,7 & 4,6 & 3,3 & 15,6 \\
\hline 8,1 & 4,3 & 2,3 & 14,8 \\
\hline 8,4 & 3,9 & 2,5 & 14,8 \\
\hline 6,5 & 5,0 & 3,2 & 14,7 \\
\hline 9,5 & 3,8 & 1,3 & 14,6 \\
\hline $7,6^{\circ}$ & 4,8 & 2,2 & 14,6 \\
\hline 7,1 & 4,3 & 3,0 & 14,4 \\
\hline 8,9 & 3,6 & 1,9 & 14,3 \\
\hline 8,2 & 4,1 & 1,5 & 13,8 \\
\hline
\end{tabular}

Source: Eurostat. European Community Household Panel.

According to 1994 ECHP wave, Greece is the population with a highest level of DFLE at birth (measured in years of life lived without disability, both for men and women. The worst figures belong to Portugal. At ages 65, Italy (men) and Germany (women) have the worst situation, and France and Luxembourg the best one. As a proportion of total life expectancy, the ranking is not exactly the same (because the differences in LE is not always the same as of the DFLE), but quite similar: Portugal, Italy, Germany and The Netherlands in the group with low proportions, and Greece, Luxembourg, Ireland and Denmark in the group with high proportions.

ECHP database also permits to calculate DFLE by level of severity. The years lived with disability are discomposed between 'moderate disability' and 'severe disability'. For all countries except France, a higher proportion of disability belongs to 'moderate disability'. For the elderly population, the proportion of severe disability tends to increase, and often becomes a dominating proportion of disability years in the last open-age interval. 


\subsection{Data}

\section{Health Data}

European Community Household Panel (ECPH) surveys provide health data from 1994 to 1998 for 11 countries: Belgium, Denmark, Germany, Ireland, Greece, Spain, France, Italy, The Netherlands, Portugal, United Kingdom.

There are some problems in the use of this Survey for cross-country comparison purposes, and even to compare the results for a country in different years. These questions are extensively discussed in the previous section, and they will not be commented here. With these problems in mind, we try to describe here the main tendencies found in the period 1994-1998.

The health related items from the ECPH questionnaire are:

a) Self-assessed health status. How is your health in general? (very good/good/fair/bad/very bad)

b) Disability. "Are you hampered in your daily activities by any chronic, physical or mental health problem, illness or disability?" (Yes, severely/Yes, to some extent/No)

Four types of health status have been estimated using these questions:

a) Good health ( = very good + good $)$

b) $\quad$ Bad health $(=$ bad + very bad $)$

c) Disability (any level) (= Yes, severely +Yes, to some extent)

d) Severe disability (= Yes, severely)

Health and Disability prevalence age groups range from 16 to $85+$ years old. Prevalence for the first age group, 16-19, have been applied to the 15-19 population group, in order to get a HE at age 15 . No HE at younger ages (0-14) have been estimated.

\section{Mortality Data}

We have used the Eurostat life tables for the EU countries available at Eurostat New Cronos Data Base. This is a unique common source available, thus it guarantees no methodological biases in the mortality basis of computation of HE. Death probabilities $\mathrm{q}(\mathrm{x})$ - and life expectancies $-\mathrm{e}(\mathrm{x})$ - at each age are the only LT series available in the New Cronos DATA BASE. We have calculated other data (survivors at each age $-1(\mathrm{x})$-, 
stationary population $\left.-\mathrm{L}(\mathrm{x})_{-}\right)$which are necessary for the application of Sullivan method of health expectancy.

However, mortality information is not available for all countries neither for all years. For year 1998 it is available only for France and Spain, and for Italy no mortality data is available for 1996-98. In order to fill this hole we have calculated respective LT using the information on deaths by sex and age, and population by sex and age available in Eurostat New Cronos DATA BASE. We have used the actuarial method of construction of LT (regular distribution of deaths between exact ages, except for the first age, to which we have applied a fixed ratio equal to $0,15-0,85)$. We were not able to know the precise methodology used by Eurostat to construct its LT. For this reason, our LT are a very fine replication of them, but not an exact reproduction. Anyway, differences are negligible and do not affect the HE calculations.

\subsection{Trends in Health Expectancies 1994-1998}

Data in the ECHP allows us thus to compute the basic Health Expectancy indicators for EU countries. This is what we do in this section through four different indicators for men and women and at age 65, that is, LEGH or Life Expectancy in Good Health, LEBH or Life Expectancy in Bad Health, DFLE or Disability Free Life Expectancy and SDFLE or Severe-Disability Free Life Expectancy. As explained before when discussing health status for EU countries, comparisons among countries are not straightforward due to several factors. On the other hand, for any given country, comparison of results through time are equally flawed due to attrition, among other causes.

\section{Life Expectancy in Good Health (LEGH).}

As shown in Table 5.2, the values of LEGH vary considerably between countries. We can organize them in three groups, including: UK, IRE, NET, DEN and BEL have highest values of LEGH; GRE, SPA and FRA are among the middle group; and ITA, GER and POR have the lowest LEGH. These groups remain the same both for males and females.

For men, expected years of life in good health have clearly increased during the studied period in Ireland, Greece and Spain. On the other hand, an evident decrease has 
been observed in France and Portugal. The other countries (BEL, DEN, GER, ITA, UK) show an erratic pattern, with no clear trends during the 1994-1998 period.

For women, the pattern is slightly different from the case of men. A clear increase is shown for Spain, Belgium and Ireland, while for Portugal and France a clear decrease has been observed. For the rest of the countries no clear patterns are observed.

\begin{tabular}{|l|c|c|c|c|c|c|c|c|c|c|}
\hline \multicolumn{10}{|c|}{ Table 5.2 } \\
Life Expectancy in Good health - LEGH (remaining years in good health after age 65) \\
\hline & \multicolumn{9}{|c|}{ Males } \\
\cline { 2 - 12 } & 1994 & 1995 & 1996 & 1997 & 1998 & 1994 & 1995 & 1996 & 1997 & 1998 \\
\hline B & 7,81 & 7,23 & 7,55 & 7,94 & 7,56 & 7,45 & 7,69 & 7,69 & 7,93 & 8,31 \\
\hline D & 3,38 & 3,52 & 2,98 & 3,32 & 3,22 & 3,12 & 3,25 & 2,92 & 2,67 & 3,25 \\
\hline DK & 7,87 & 8,21 & 8,20 & 8,11 & 7,84 & 8,36 & 8,11 & 8,27 & 8,36 & 8,64 \\
\hline E & 4,89 & 5,65 & 5,65 & 5,77 & 5,80 & 4,50 & 5,06 & 5,13 & 5,20 & 5,25 \\
\hline F & 5,74 & 5,16 & 5,35 & 5,11 & 4,98 & 5,77 & 5,09 & 5,26 & 5,52 & 5,03 \\
\hline GR & 5,12 & 5,35 & 6,00 & 5,96 & 6,51 & 4,73 & 4,73 & 5,58 & 4,60 & 5,52 \\
\hline I & 3,64 & 3,54 & 3,64 & 3,79 & 3,50 & 3,34 & 3,57 & 3,21 & 3,68 & 3,31 \\
\hline IRL & 7,45 & 7,44 & 8,30 & 8,51 & 8,29 & 8,10 & 8,59 & 8,34 & 9,55 & 9,51 \\
\hline NL & 7,55 & 7,78 & 7,36 & 7,91 & 8,29 & 8,44 & 8,38 & 8,12 & 8,46 & 8,11 \\
\hline P & 2,67 & 2,40 & 2,04 & 1,92 & 1,68 & 2,01 & 1,62 & 1,34 & 1,08 & 1,01 \\
\hline UK & 8,99 & 9,15 & 9,59 & 9,25 & 8,83 & 8,74 & 8,51 & 9,04 & 8,67 & 9,83 \\
\hline Source: & EUROSTAT-ECHP and own computations \\
\hline
\end{tabular}

Life Expectancy in Bad Health (LEBH).

Trends in LEBH are shown in Table 5.3 below and are, in general, symmetric to the good health ones (as the former increases, the latter decreases). But there are some exceptions because the middle category ('fair') is not included in either of them. The population share of 'fair' health has varied across the countries and over time.

Both the number of years lived in bad health and its proportion over the total life expectancy are in general greater among females than among males.

The longest time in bad health for male population is found in Portugal and Italy, while the shortest time in bad health is observed in the UK, Denmark, Belgium, Ireland and the Netherlands. For the female population the grouping is not so clear.

Time trends for male LEBH show a pair of countries with increasing years lived in bad health (Portugal and France); two countries with a clear and strong decrease (Ireland and Spain); Italy with a slight decrease; and the rest of countries with an erratic or unstable pattern. 
On the other hand, time trends for female LEBH show increasing values in Portugal and the UK, a clear decrease in Spain, Greece and Ireland, a certain decrease in Denmark and Belgium, and an absence of any pattern in Italy, the Netherlands and France.

\begin{tabular}{|l|c|c|c|c|c|c|c|c|c|c|}
\hline \multicolumn{10}{|c|}{ Table 5.3 } \\
\hline \multicolumn{10}{|c|}{ Life Expectancy in Bad health - LEBH (remaining years in bad health after age 65) } \\
\hline & & \multicolumn{10}{|c|}{ Males } & & & \multicolumn{7}{|c|}{ Females } \\
\hline & 1994 & 1995 & 1996 & 1997 & 1998 & 1994 & 1995 & 1996 & 1997 & 1998 \\
\hline B & 1,61 & 1,52 & 1,56 & 1,73 & 1,64 & 3,49 & 2,93 & 3,11 & 2,91 & 2,98 \\
\hline D & 4,82 & 5,07 & 4,78 & 4,55 & 4,79 & 6,34 & 6,53 & 6,54 & 6,38 & 7,60 \\
\hline DK & 1,98 & 1,57 & 2,20 & 1,73 & 2,03 & 3,55 & 3,36 & 4,18 & 3,75 & 2,91 \\
\hline E & 5,06 & 4,81 & 4,31 & 4,44 & 4,31 & 8,19 & 7,86 & 6,89 & 7,14 & 7,03 \\
\hline F & 2,82 & 2,67 & 2,79 & 3,02 & 3,28 & 4,50 & 4,79 & 4,08 & 4,41 & 4,55 \\
\hline GR & 5,04 & 4,42 & 3,65 & 4,30 & 4,05 & 6,66 & 5,09 & 5,33 & 5,44 & 5,06 \\
\hline I & 5,60 & 5,45 & 5,41 & 5,49 & 5,35 & 8,20 & 8,26 & 7,96 & 8,20 & 8,40 \\
\hline Irl & 1,53 & 1,28 & 1,10 & 0,98 & 0,81 & 2,47 & 1,99 & 1,95 & 2,38 & 1,73 \\
\hline NL & 1,48 & 1,17 & 1,19 & 1,23 & 0,93 & 2,01 & 2,37 & 2,24 & 2,28 & 2,14 \\
\hline P & 6,58 & 6,42 & 6,97 & 7,10 & 6,87 & 9,74 & 9,75 & 10,57 & 10,64 & 10,63 \\
\hline UK & 2,02 & 1,73 & 1,46 & 1,80 & 2,06 & 2,08 & 2,38 & 2,31 & 2,54 & 3,16 \\
\hline Source: EUROSTAT-ECHP and own computations \\
\hline
\end{tabular}

\section{Disability Free Life Expectancy (DFLE).}

Globally speaking, cross-country differences in DFLE are smaller than in the case of LEGH or LEBH, with the exception of two countries: the UK, with a higher level relative to other countries, and Germany clearly below the level of others. This can be seen in Table 5.4 below.

Most of the countries show an increase of DFLE. But it seems that a certain problem exists with the data for 1994. Both for males and females, values in 1994 are substantially smaller than for the rest of years. Only France has the opposite situation. We must remember there was a slight change in the questionnaire from 1995; in 1994 there was only one question regarding disability, while from 1995 the same question is divided into two, the existence of disability and the severity.

During the five year period observed in ECHP surveys, DFLE tends to increase in most of the countries except for France. But if we don't take into account the year 1994, trends in DFLE become more complex. Both for males and females, an increase in DFLE is observed in Spain, Greece, Ireland and Italy, while a decrease is observed in Denmark, Belgium, the UK, Portugal and France. 


\begin{tabular}{|l|c|c|c|c|c|c|c|c|c|c|}
\hline \multicolumn{10}{|c|}{ Table 5.4 } \\
Disability Free Life Expectancy - DFLE (remaining years free of disability after age 65) \\
\hline & \multicolumn{10}{|c|}{ Males } \\
\cline { 2 - 13 } & 1994 & 1995 & 1996 & 1997 & 1998 & 1994 & 1995 & 1996 & 1997 & 1998 \\
\hline B & 8,03 & 9,98 & 9,71 & 10,76 & 8,97 & 9,01 & 11,95 & 12,45 & 12,42 & 10,34 \\
\hline D & & 4,17 & 4,59 & 4,75 & 4,35 & & 6,91 & 7,34 & 7,08 & 5,14 \\
\hline DK & 9,03 & 9,41 & 8,83 & 9,04 & 9,05 & 9,12 & 9,33 & 9,41 & 8,91 & 9,82 \\
\hline E & 9,08 & 9,94 & 10,58 & 10,57 & 10,32 & 9,21 & 11,24 & 11,08 & 11,42 & 11,42 \\
\hline F & 8,89 & 7,53 & 7,38 & 7,72 & 7,17 & 10,28 & 8,24 & 8,55 & 8,99 & 8,91 \\
\hline GR & 8,75 & 9,83 & 10,34 & 9,96 & 10,15 & 9,82 & 11,55 & 11,82 & 11,20 & 11,42 \\
\hline I & 7,41 & 10,21 & 10,12 & 10,68 & 10,50 & 7,31 & 11,51 & 11,91 & 12,17 & 11,95 \\
\hline Irl & 7,89 & 9,03 & 9,59 & 9,16 & 9,86 & 9,37 & 10,62 & 10,40 & 10,56 & 11,32 \\
\hline NL & 8,46 & 9,33 & 9,39 & 9,25 & 9,20 & 8,67 & 10,59 & 10,58 & 10,78 & 10,27 \\
\hline P & 7,36 & 8,28 & 7,41 & 8,00 & 7,83 & 8,06 & 9,98 & 8,45 & 8,81 & 8,60 \\
\hline UK & 10,61 & 11,48 & 11,49 & 11,34 & 10,99 & 12,99 & 13,60 & 13,91 & 13,54 & 12,48 \\
\hline Source: EUROSTAT-ECHP and own computations \\
\hline
\end{tabular}

Severe-Disability Free Life Expectancy (SDFLE).

Table 5.5 shows how SDFLE has in general more erratic trends than DFLE. According to ECPH, Spain is the country with the most years free of severe disability after age 65 during the whole period (1994-98) and both for males and females. On the other hand, the UK, Portugal and Germany have the least years free of severe disability at age 65 of all countries.

\begin{tabular}{|c|c|c|c|c|c|c|c|c|c|c|}
\hline & & $\begin{array}{r}\text { Seve } \\
\text { (remail }\end{array}$ & $\begin{array}{l}\text { e Disab } \\
\text { ing year }\end{array}$ & $\begin{array}{l}\text { lity } \mathrm{Fr} \\
\text { s free } 0\end{array}$ & $\begin{array}{l}\text { able } 5.5 \\
\text { Life } \mathbf{E} \\
\text { severe }\end{array}$ & $\begin{array}{l}\text { xpectan } \\
\text { disabili }\end{array}$ & $\begin{array}{l}y-S I \\
y \text { aftel }\end{array}$ & $\begin{array}{l}\text { LE } \\
\text { ge } 65 \text { ) }\end{array}$ & & \\
\hline & & & Males & & & & & Female & & \\
\hline & 1994 & 1995 & 1996 & 1997 & 1998 & 1994 & 1995 & 1996 & 1997 & 1998 \\
\hline $\mathrm{B}$ & 12,51 & 12,75 & 12,52 & 13,32 & 10,99 & 15,06 & 15,17 & 15,20 & 15,92 & 13,32 \\
\hline D & & 10,87 & 11,30 & 12,30 & 11,42 & & 14,34 & 14,35 & 14,88 & 13,58 \\
\hline DK & 12,54 & 12,26 & 12,09 & 12,62 & 12,51 & 14,62 & 14,17 & 13,96 & 14,03 & 14,56 \\
\hline $\mathrm{E}$ & 13,66 & 13,44 & 13,80 & 13,97 & 13,75 & 15,47 & 15,70 & 16,39 & 16,46 & 16,13 \\
\hline $\mathrm{F}$ & 11,94 & 11,67 & 11,69 & 11,61 & 11,82 & 14,62 & 14,27 & 14,81 & 14,46 & 14,37 \\
\hline GR & 13,12 & 12,83 & 13,60 & 13,47 & 13,08 & 14,88 & 15,03 & 15,26 & 15,20 & 14,95 \\
\hline I & 12,25 & 12,85 & 13,38 & 13,54 & 13,41 & 13,99 & 14,62 & 16,06 & 15,87 & 15,90 \\
\hline Irl & 12,12 & 11,88 & 12,69 & 12,62 & 12,96 & 14,85 & 14,88 & 14,99 & 15,08 & 16,22 \\
\hline $\mathrm{NL}$ & 12,34 & 12,78 & 12,36 & 12,86 & 12,50 & 15,17 & 15,43 & 15,51 & 15,57 & 15,35 \\
\hline $\mathrm{P}$ & 11,37 & 11,37 & 10,69 & 10,85 & 11,10 & 13,95 & 13,90 & 13,15 & 13,17 & 12,97 \\
\hline UK & 10,61 & 11,48 & 11,49 & 11,34 & 10,99 & 12,99 & 13,60 & 13,91 & 13,54 & 12,48 \\
\hline
\end{tabular}




\section{Summing up}

Globally speaking, we find a great divergence of trends between countries and few clear trends. However, we may distinguish certain groups of countries. Spain, Ireland, Greece and Italy seem to improve their health (increase of DFLE and LEGH, decrease of LEBH), while Portugal and France show a deteriorating trend in their health. We don't know if this is a genuine picture of the health status of the EU population, or the results of other factors such as culture, social norm and measurement errors imbedded in health data. We think it is difficult under this circumstance to establish any coherent set of hypothesis for projections of health status based on past trends.

\subsection{How HE relates to LE?}

In this section we examine the relationship between life expectancy and health expectancy for the years 1994-1998 for which we have data for health status (ECHP). The purpose of this exercise is to see if there is any consistent and reasonable relationship between the two which can be used for the projection of health expectancies. Life expectancy data for the years 1994 to 1998 are obtained from Eurostat New Cronos data base. Health expectancies for each year are computed combining the life expectancy and health prevalence data from ECHP by Sullivan method. We computed the HE at age 15 . We compare life expectancy with several measures of health expectancy, in good health, disability free, and severe-disability free. For each comparison, we have 55 data points (11 countries for 5 years, 1994-1998).

\section{Life expectancy in good health vs. LE}

As shown in Figures 5.1 and 5.2, there is a big dispersion of the observations without any particular pattern, and most linear regression lines are insignificant. Furthermore, the correlation coefficients are small and insignificant. If we interpret literally the regression results, a one year increase in LE for men at age 15 increase LE in good health by 2 year, while it decreases the LE in good health for women by one year. 


\section{Figure 5.1}

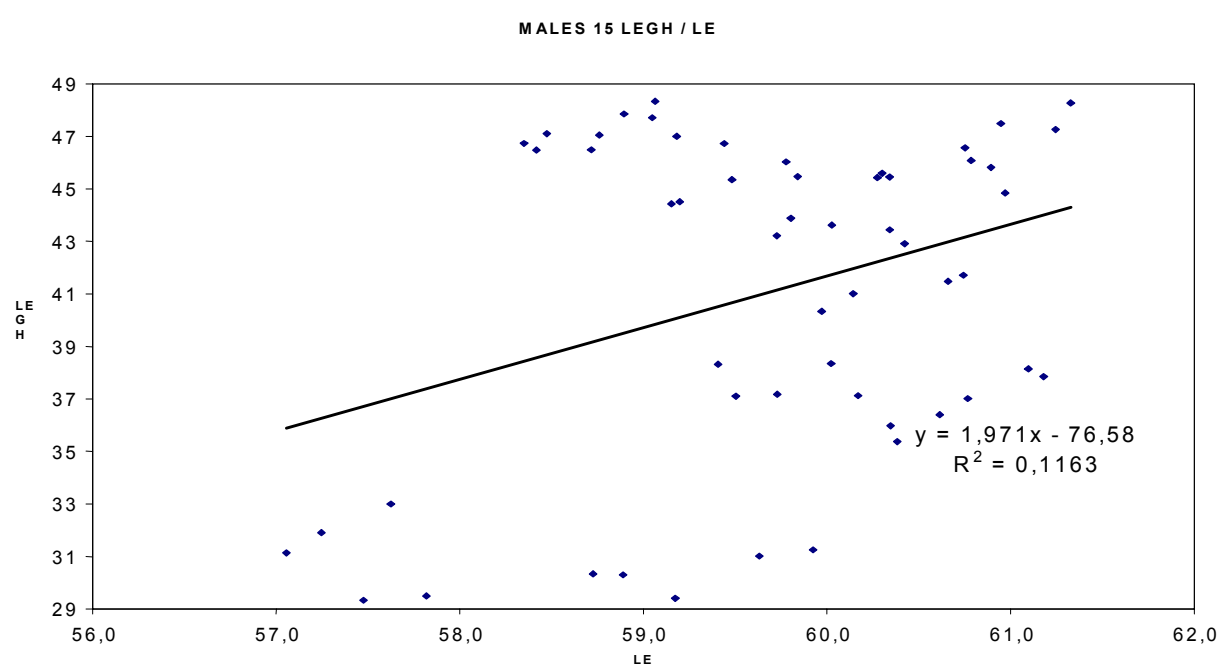

Figure 5.2

FEMALES 15 LEGH / LE

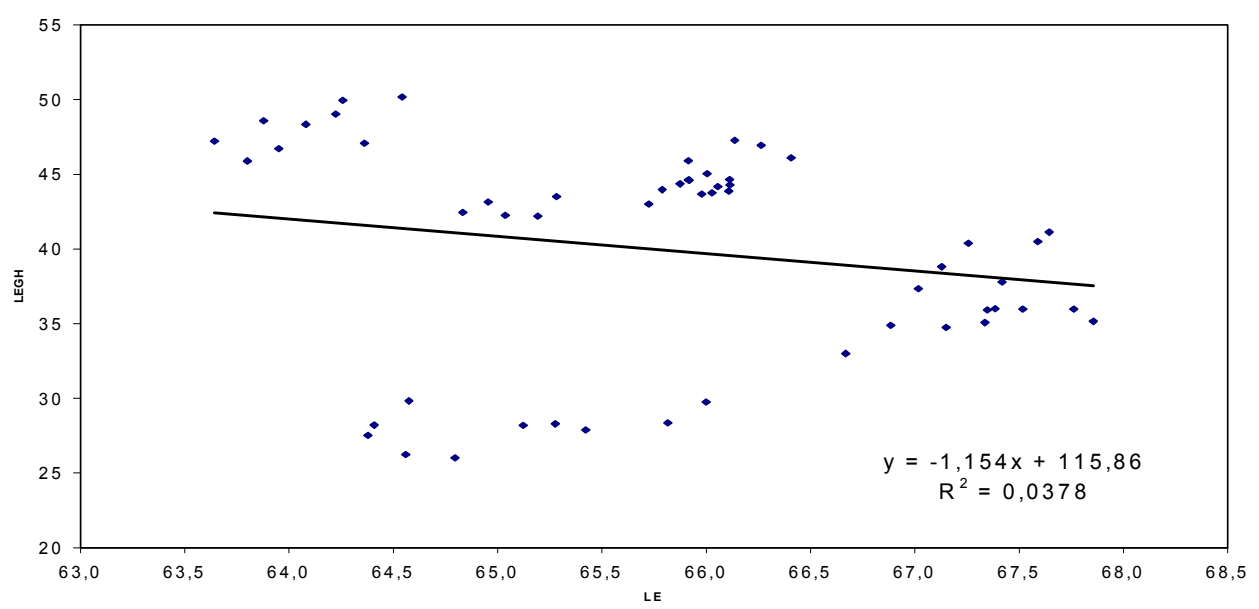

Disability Free Life expectancy vs. LE

Figures 5.3 and 5.4 show again that there is also a big dispersion of the observations. For the case of men, the regression line is relatively significant with a coefficient close to 2, suggesting that one year increase in LE increases disability free life expectancy by 2 years. For women it is close to zero, suggesting that disability free life expectancy is irrelevant to the changes in life expectancy. 
Figure 5.3

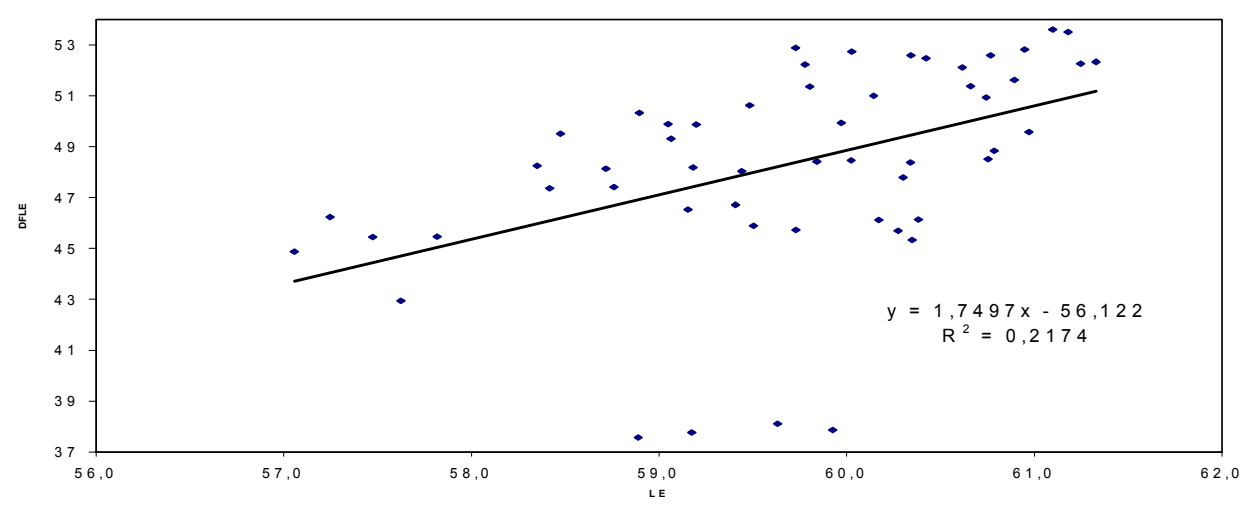

Figure 5.4

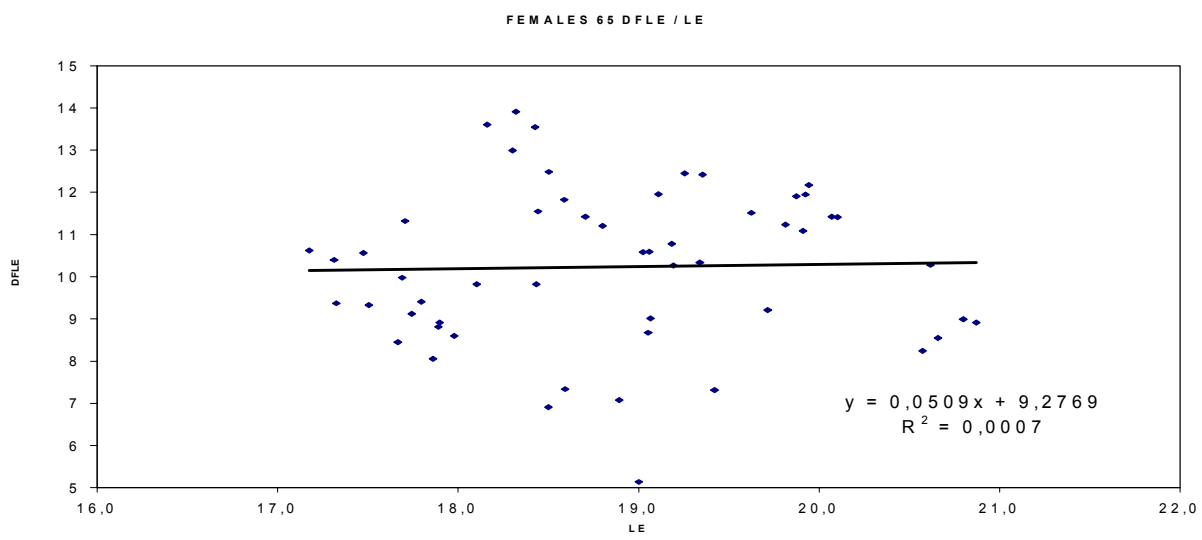

Severe-Disability Free Life expectancy vs. LE

Once more. Figures 5.5 and 5.6 tell us that there is a big dispersion of the observations without any consistent relationship behind also in what concerns our measure of SDFL and life expectancy.

Figure 5.5

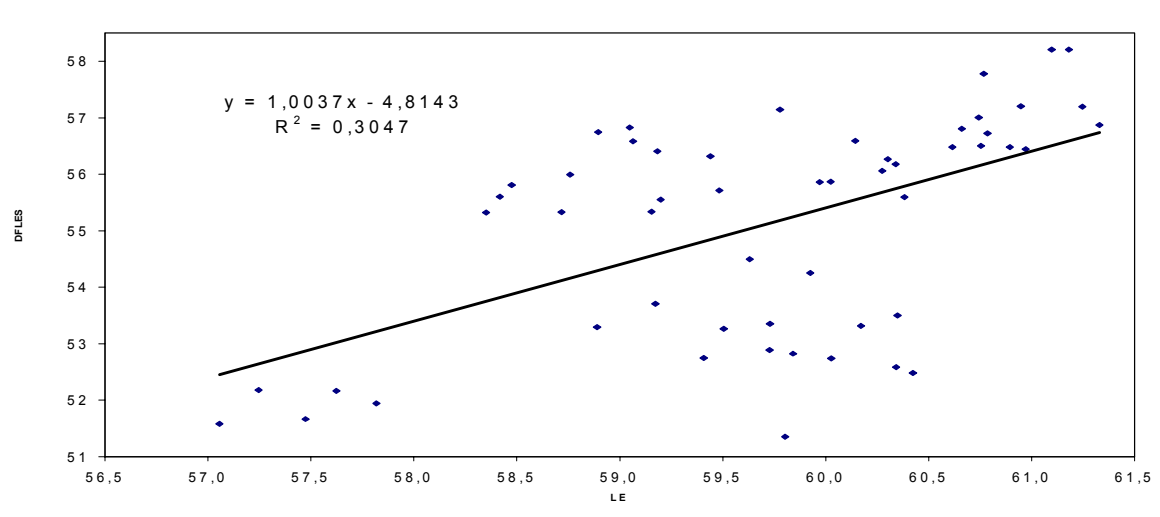




\section{Figure 5.6}

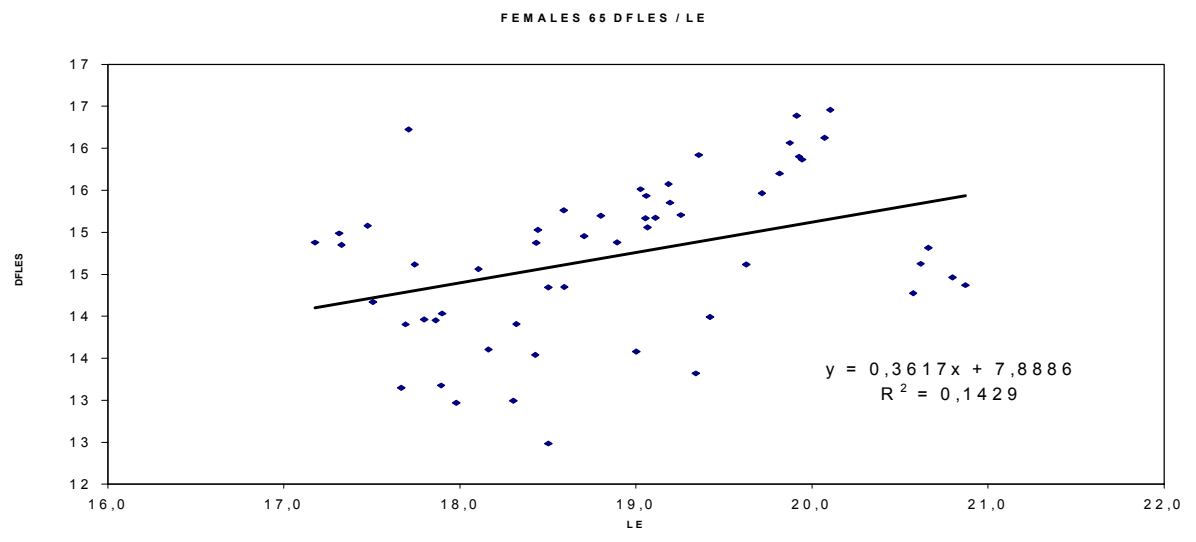

The analysis above analysis clearly suggests that we can not rely on the observed relationship between LE and $\mathrm{HE}$ for the purpose of projecting health expectancies

\subsection{Conventional scenarios for Health Adjusted Life Expectancy}

Given the absence of sensible patterns among Health Expectancies and Life Expectancies out of the ECHP data, a simple but consistent procedure is used to create Health Expectancy scenarios for EU countries. We define three indicators of health expectancy: in good health, disability free, and severe-disability free. Computations are made at ages 15 and 65 .

With respect to trend in health status in the future, we explore two variants. The first one assumes that the proportion of HE over LE stays constant at the average level of the period 1994-1998. This we call also "constant relative morbidity" hypothesis. The second one assumes that the years in an unhealthy state (not in good health or with disability) remain constant at the average level of the period 1994-1998 or "constant absolute morbidity" hypothesis.

The first assumption implies that any indicator of health expectancy either for men or women, at age 15 or 65 , increases in the same proportion as life expectancy for any gender and age, thus keeping constant the ratio between HE and LE. The second assumption implies that HE increases by the same number of years as LE does, thus implying that any gain in life years is free of health and disability problems.

These two scenarios, that we would not call projections, respectively, would likely capture the lower and upper trends one could expect concerning future advances in healthy life expectancies. The results for EU countries present in the ECHP (except Luxembourg) 
are shown in Tables 5.6 and 5.7, where estimates for 1996 have been obtained out of observed data whereas estimates for the projections for 2010 and 2025. As such these scenarios keep on average the country differences in health adjusted life expectancies observed in the nineties (1994-1998). 
Table 5.6

Scenarios for Health Expectancies. Constant relative morbidity hypothesis

\begin{tabular}{|c|c|c|c|c|c|c|c|c|c|}
\hline & & \multicolumn{2}{|r|}{ Females } & \multicolumn{2}{|l|}{ Age 15} & \multicolumn{2}{|r|}{ Females } & \multicolumn{2}{|l|}{ Age 65} \\
\hline \multirow{2}{*}{ BEL } & 1996 & 66,03 & 43,77 & 54,77 & 60,65 & 19,26 & 7,69 & 12,45 & 15,20 \\
\hline & 2025 & 69,80 & 47,70 & 56,10 & 63,58 & 21,64 & 10,23 & 13,65 & 17,35 \\
\hline \multirow{3}{*}{ DEN } & 1996 & 63,80 & 45,90 & 47,24 & 58,60 & 17,80 & 8,27 & 9,41 & 13,96 \\
\hline & 2010 & 65,56 & 47,79 & 48,31 & 59,96 & 19,04 & 9,58 & 10,55 & 15,50 \\
\hline & 2025 & 67,09 & 49,33 & 49,85 & 61,50 & 20,07 & 10,60 & 11,57 & 16,52 \\
\hline \multirow[t]{2}{*}{ GER } & 2010 & 67,81 & 30,78 & 40,99 & 60,90 & 20,12 & 4,49 & 8,07 & 15,74 \\
\hline & 2025 & 69,35 & 32,32 & 42,53 & 62,44 & 21,26 & 5,63 & 9,20 & 16,87 \\
\hline \multirow{3}{*}{ GRE } & 1996 & 66,14 & 47,28 & 55,77 & 61,61 & 18,59 & 5,58 & 11,82 & 15,26 \\
\hline & 2010 & 68,09 & 47,74 & 56,29 & 63,02 & 20,02 & 6,46 & 12,59 & 16,49 \\
\hline & 2025 & 69,59 & 49,25 & 57,79 & 64,52 & 21,16 & 7,60 & 13,73 & 17,63 \\
\hline \multirow{3}{*}{ SPA } & 1996 & 67,26 & 40,39 & 53,79 & 62,46 & 19,91 & 5,13 & 11,08 & 16,39 \\
\hline & 2010 & 68,97 & 41,28 & 54,52 & 63,62 & 21,04 & 6,15 & 11,99 & 17,15 \\
\hline & 2025 & 70,10 & 42,41 & 55,65 & 64,75 & 21,86 & 6,96 & 12,81 & 17,96 \\
\hline & 1996 & 67,52 & 35,97 & 48,57 & 59,24 & 20,66 & 5,26 & 8,55 & 14,81 \\
\hline FRA & 2010 & 69,75 & 38,35 & 51,28 & 60,89 & 22,04 & 6,67 & 10,33 & 15,84 \\
\hline & 2025 & 71,34 & 39,94 & 52,87 & 62,48 & 23,15 & 7,78 & 11,45 & 16,96 \\
\hline & \begin{tabular}{l|l|}
1996 \\
\end{tabular} & 64,22 & 49,04 & 52,84 & 61,01 & 17,31 & 8,34 & 10,40 & 14,99 \\
\hline IRE & 2010 & 66,52 & 51,55 & 54,53 & 63,49 & 19,07 & 10,49 & 12,13 & 16,87 \\
\hline & 2025 & 68,27 & 53,30 & 56,27 & 65,23 & 20,34 & 11,76 & 13,40 & 18,14 \\
\hline & 1996 & 67,15 & 34,75 & 55,92 & 62,48 & 19,87 & 3,21 & 11,91 & 16,06 \\
\hline ITA & 2010 & 69,05 & 36,70 & 56,18 & 63,42 & 21,06 & 4,73 & 12,27 & 16,59 \\
\hline & 2025 & 70,51 & 38,16 & 57,63 & 64,88 & 22,17 & 5,83 & 13,38 & 17,70 \\
\hline & 1996 & 65,92 & 44,61 & 48,43 & 59,59 & 19,03 & 8,12 & 10,58 & 15,51 \\
\hline NET & 2010 & 67,57 & 46,02 & 49,45 & 61,29 & 20,14 & 9,34 & 11,22 & 16,45 \\
\hline & 2025 & 69,11 & 47,55 & 50,99 & 62,83 & 21,25 & 10,45 & 12,33 & 17,56 \\
\hline & 1996 & 64,38 & 27,53 & 47,31 & 57,06 & 17,67 & 1,34 & 8,45 & 13,15 \\
\hline POR & 2010 & 66,39 & 29,41 & 49,35 & 59,30 & 18,78 & 2,37 & 9,74 & 14,39 \\
\hline & 2025 & 68,19 & 31,21 & 51,14 & 61,10 & 20,05 & 3,65 & 11,01 & 15,66 \\
\hline & 1996 & 65,04 & 42,26 & 56,08 & & 18,32 & 9,04 & 13,91 & \\
\hline UK & 2010 & 67,18 & 44,84 & 57,57 & & 19,70 & 10,32 & 14,67 & \\
\hline & 2025 & 69,06 & 46,71 & 59,44 & & 21,10 & 11,72 & 16,06 & \\
\hline & & & Males & Age 15 & & & Males & Age 65 & \\
\hline & & LE 15M & LEGH 15M & DFLE 15M & DFLES 15M & LE 65M & LEGH 65M & DFLE 65M & DFLES 65M \\
\hline & 1996 & 59,48 & 45,34 & 50,63 & 55,71 & 14,96 & 7,55 & 9,71 & 12,52 \\
\hline BEL & 2010 & 62,76 & 48,42 & 52,80 & 58,58 & 16,78 & 9,42 & 11,29 & 14,22 \\
\hline & 2025 & 64,79 & 50,45 & 54,83 & 60,61 & 18,10 & 10,73 & 12,61 & 15,53 \\
\hline & 1996 & 58,72 & 46,49 & 48,14 & 55,33 & 14,35 & 8,20 & 8,83 & 12,09 \\
\hline DEN & 2010 & 61,53 & 49,39 & 50,70 & 58,50 & 15,95 & 9,56 & 10,59 & 13,92 \\
\hline & 2025 & 63,43 & 51,30 & 52,61 & 60,41 & 17,18 & 10,80 & 11,82 & 15,16 \\
\hline & 1996 & 59,17 & 29,41 & 37,77 & 53,71 & 14,87 & 2,98 & 4,59 & 11,30 \\
\hline GER & 2010 & 62,21 & 33,40 & 40,77 & 56,88 & 16,57 & 4,92 & 6,11 & 13,11 \\
\hline & 2025 & 64,20 & 35,39 & 42,76 & 58,87 & 17,87 & 6,23 & 7,41 & 14,41 \\
\hline & 1996 & 60,95 & 47,49 & 52,83 & 57,20 & 16,15 & 6,00 & 10,34 & 13,60 \\
\hline GRE & 2010 & 63,48 & 49,14 & 54,12 & 59,24 & 17,53 & 7,08 & 11,10 & 14,51 \\
\hline & 2025 & 65,39 & 51,04 & 56,03 & 61,15 & 18,82 & 8,36 & 12,38 & 15,80 \\
\hline & 1996 & 60,14 & 41,01 & 51,00 & 56,59 & 16,08 & 5,65 & 10,58 & 13,80 \\
\hline SPA & 2010 & 61,70 & 41,97 & 51,74 & 57,82 & 16,82 & 6,29 & 10,83 & 14,46 \\
\hline & 2025 & 63,27 & 43,54 & 53,30 & 59,39 & 17,77 & 7,24 & 11,79 & 15,41 \\
\hline & 1996 & 59,73 & 37,18 & 45,74 & 53,35 & 16,12 & 5,35 & 7,38 & 11,69 \\
\hline FRA & 2010 & 62,43 & 39,74 & 48,56 & 55,84 & 17,65 & 6,71 & 9,18 & 13,19 \\
\hline & 2025 & 64,44 & 41,75 & 50,57 & 57,84 & 18,84 & 7,90 & 10,37 & 14,38 \\
\hline & 1996 & 58,90 & 47,85 & 50,33 & 56,75 & 13,83 & 8,30 & 9,59 & 12,69 \\
\hline IRE & 2010 & 61,44 & 50,20 & 51,89 & 58,99 & 15,36 & 9,48 & 10,59 & 13,94 \\
\hline & 2025 & 63,36 & 52,12 & 53,81 & 60,91 & 16,67 & 10,79 & 11,89 & 15,24 \\
\hline & 1996 & 60,77 & 37,02 & 52,59 & 57,78 & 15,71 & 3,64 & 10,12 & 13,38 \\
\hline ITA & 2010 & 63,20 & 39,35 & 53,98 & 59,65 & 17,30 & 5,18 & 11,34 & 14,64 \\
\hline & 2025 & 65,24 & 41,39 & 56,02 & 61,69 & 18,66 & 6,53 & 12,69 & 15,99 \\
\hline & 1996 & 60,34 & 45,45 & 48,38 & 56,18 & 14,75 & 7,36 & 9,39 & 12,36 \\
\hline NET & 2010 & 62,59 & 47,92 & 49,94 & 58,45 & 16,23 & 9,14 & 10,49 & 13,94 \\
\hline & 2025 & 64,31 & 49,64 & 51,66 & 60,17 & 17,43 & 10,34 & 11,69 & 15,13 \\
\hline & 1996 & 57,06 & 31,13 & 44,88 & 51,58 & 14,19 & 2,04 & 7,41 & 10,69 \\
\hline POR & 2010 & 59,76 & 33,28 & 47,30 & 54,22 & 15,25 & 3,01 & 8,64 & 11,94 \\
\hline & 2025 & 61,97 & 35,50 & 49,52 & 56,44 & 16,55 & 4,30 & 9,93 & 13,23 \\
\hline & 1996 & 60,03 & 43,62 & 52,74 & & 14,85 & 9,59 & 11,49 & \\
\hline UK & 2010 & 62,59 & 45,94 & 54,93 & & 16,26 & 10,56 & 12,58 & \\
\hline & 2025 & 64,45 & 47,79 & 56,79 & & 17,54 & 11,84 & 13,87 & \\
\hline
\end{tabular}

Source: Own computations 
Table 5.7

Scenarios for Health Expectancies. Constant absolute morbidity hypothesis

\begin{tabular}{|c|c|c|c|c|c|c|c|c|c|}
\hline & & \multicolumn{2}{|r|}{ Females } & \multicolumn{2}{|l|}{ Age 15} & \multicolumn{2}{|r|}{ Females } & \multicolumn{2}{|l|}{ Age 65} \\
\hline \multirow{2}{*}{ BEL } & 1996 & 66,03 & 43,77 & 54,77 & 60,65 & 19,26 & 7,69 & 12,45 & 15,20 \\
\hline & 2025 & 69,80 & 46,41 & 55,30 & 63,21 & 21,64 & 8,80 & 12,65 & 16,81 \\
\hline \multirow{3}{*}{ DEN } & 1996 & 63,80 & 45,90 & 47,24 & 58,60 & 17,80 & 8,27 & 9,41 & 13,96 \\
\hline & 2010 & 65,56 & 47,45 & 47,99 & 59,85 & 19,04 & 8,93 & 9,96 & 15,25 \\
\hline & 2025 & 67,09 & 48,57 & 49,11 & 61,26 & 20,07 & 9,41 & 10,50 & 16,08 \\
\hline \multirow[t]{2}{*}{ GER } & 2010 & 67,81 & 29,49 & 40,05 & 60,66 & 20,12 & 3,28 & 7,13 & 15,40 \\
\hline & 2025 & 69,35 & 30,16 & 40,96 & 62,04 & 21,26 & 3,47 & 7,53 & 16,27 \\
\hline \multirow{3}{*}{ GRE } & 1996 & 66,14 & 47,28 & 55,77 & 61,61 & 18,59 & 5,58 & 11,82 & 15,26 \\
\hline & 2010 & 68,09 & 47,15 & 55,95 & 62,87 & 20,02 & 5,42 & 12,02 & 16,22 \\
\hline & 2025 & 69,59 & 48,19 & 57,18 & 64,26 & 21,16 & 5,73 & 12,70 & 17,15 \\
\hline \multirow{3}{*}{ SPA } & 1996 & 67,26 & 40,39 & 53,79 & 62,46 & 19,91 & 5,13 & 11,08 & 16,39 \\
\hline & 2010 & 68,97 & 40,60 & 54,16 & 63,49 & 21,04 & 5,31 & 11,49 & 16,93 \\
\hline & 2025 & 70,10 & 41,27 & 55,05 & 64,53 & 21,86 & 5,52 & 11,93 & 17,58 \\
\hline & 1996 & 67,52 & 35,97 & 48,57 & 59,24 & 20,66 & 5,26 & 8,55 & 14,81 \\
\hline FRA & 2010 & 69,75 & 37,34 & 50,69 & 60,61 & 22,04 & 5,68 & 9,57 & 15,44 \\
\hline & 2025 & 71,34 & 38,19 & 51,84 & 61,99 & 23,15 & 5,97 & 10,06 & 16,23 \\
\hline & \begin{tabular}{l|l|}
1996 \\
\end{tabular} & 64,22 & 49,04 & 52,84 & 61,01 & 17,31 & 8,34 & 10,40 & 14,99 \\
\hline IRE & 2010 & 66,52 & 51,01 & 54,09 & 63,38 & 19,07 & 9,66 & 11,46 & 16,66 \\
\hline & 2025 & 68,27 & 52,35 & 55,51 & 65,04 & 20,34 & 10,31 & 12,22 & 17,77 \\
\hline & 1996 & 67,15 & 34,75 & 55,92 & 62,48 & 19,87 & 3,21 & 11,91 & 16,06 \\
\hline ITA & 2010 & 69,05 & 35,75 & 55,80 & 63,26 & 21,06 & 3,65 & 11,69 & 16,30 \\
\hline & 2025 & 70,51 & 36,50 & 56,97 & 64,59 & 22,17 & 3,84 & 12,31 & 17,15 \\
\hline & 1996 & 65,92 & 44,61 & 48,43 & 59,59 & 19,03 & 8,12 & 10,58 & 15,51 \\
\hline NET & 2010 & 67,57 & 45,49 & 49,01 & 61,14 & 20,14 & 8,75 & 10,73 & 16,25 \\
\hline & 2025 & 69,11 & 46,53 & 50,13 & 62,53 & 21,25 & 9,24 & 11,32 & 17,14 \\
\hline & 1996 & 64,38 & 27,53 & 47,31 & 57,06 & 17,67 & 1,34 & 8,45 & 13,15 \\
\hline POR & 2010 & 66,39 & 28,35 & 48,86 & 59,10 & 18,78 & 1,49 & 9,25 & 14,15 \\
\hline & 2025 & 68,19 & 29,12 & 50,18 & 60,70 & 20,05 & 1,59 & 9,88 & 15,11 \\
\hline & 1996 & 65,04 & 42,26 & 56,08 & & 18,32 & 9,04 & 13,91 & \\
\hline UK & 2010 & 67,18 & 44,11 & 57,25 & & 19,70 & 9,62 & 14,29 & \\
\hline & 2025 & 69,06 & 45,34 & 58,85 & & 21,10 & 10,31 & 15,30 & \\
\hline & & & Males & Age 15 & & & Males & Age 65 & \\
\hline & & LE 15M & LEGH 15M & DFLE 15M & DFLES 15M & LE 65M & LEGH 65M & DFLE 65M & DFLES 65M \\
\hline & 1996 & 59,48 & 45,34 & 50,63 & 55,71 & 14,96 & 7,55 & 9,71 & 12,52 \\
\hline BEL & 2010 & 62,76 & 47,63 & 52,25 & 58,35 & 16,78 & 8,53 & 10,63 & 13,91 \\
\hline & 2025 & 64,79 & 49,17 & 53,94 & 60,24 & 18,10 & 9,20 & 11,46 & 15,00 \\
\hline & 1996 & 58,72 & 46,49 & 48,14 & 55,33 & 14,35 & 8,20 & 8,83 & 12,09 \\
\hline DEN & 2010 & 61,53 & 48,83 & 50,20 & 58,36 & 15,95 & 8,89 & 10,03 & 13,71 \\
\hline & 2025 & 63,43 & 50,34 & 51,76 & 60,17 & 17,18 & 9,58 & 10,80 & 14,77 \\
\hline & 1996 & 59,17 & 29,41 & 37,77 & 53,71 & 14,87 & 2,98 & 4,59 & 11,30 \\
\hline GER & 2010 & 62,21 & 31,97 & 39,71 & 56,61 & 16,57 & 3,64 & 4,95 & 12,73 \\
\hline & 2025 & 64,20 & 32,99 & 40,98 & 58,43 & 17,87 & 3,93 & 5,34 & 13,73 \\
\hline & 1996 & 60,95 & 47,49 & 52,83 & 57,20 & 16,15 & 6,00 & 10,34 & 13,60 \\
\hline GRE & 2010 & 63,48 & 48,57 & 53,76 & 59,07 & 17,53 & 6,25 & 10,59 & 14,27 \\
\hline & 2025 & 65,39 & 50,03 & 55,37 & 60,85 & 18,82 & 6,71 & 11,36 & 15,32 \\
\hline & 1996 & 60,14 & 41,01 & 51,00 & 56,59 & 16,08 & 5,65 & 10,58 & 13,80 \\
\hline SPA & 2010 & 61,70 & 41,51 & 51,50 & 57,73 & 16,82 & 5,81 & 10,56 & 14,35 \\
\hline & 2025 & 63,27 & 42,57 & 52,81 & 59,20 & 17,77 & 6,14 & 11,16 & 15,16 \\
\hline & 1996 & 59,73 & 37,18 & 45,74 & 53,35 & 16,12 & 5,35 & 7,38 & 11,69 \\
\hline FRA & 2010 & 62,43 & 38,75 & 47,96 & 55,55 & 17,65 & 5,74 & 8,42 & 12,79 \\
\hline & 2025 & 64,44 & 40,00 & 49,50 & 57,33 & 18,84 & 6,12 & 8,99 & 13,65 \\
\hline & 1996 & 58,90 & 47,85 & 50,33 & 56,75 & 13,83 & 8,30 & 9,59 & 12,69 \\
\hline IRE & 2010 & 61,44 & 49,71 & 51,47 & 58,88 & 15,36 & 8,85 & 10,08 & 13,79 \\
\hline & 2025 & 63,36 & 51,26 & 53,07 & 60,72 & 16,67 & 9,61 & 10,94 & 14,96 \\
\hline & 1996 & 60,77 & 37,02 & 52,59 & 57,78 & 15,71 & 3,64 & 10,12 & 13,38 \\
\hline ITA & 2010 & 63,20 & 38,41 & 53,62 & 59,51 & 17,30 & 3,98 & 10,75 & 14,38 \\
\hline & 2025 & 65,24 & 39,65 & 55,35 & 61,43 & 18,66 & 4,29 & 11,59 & 15,50 \\
\hline & 1996 & 60,34 & 45,45 & 48,38 & 56,18 & 14,75 & 7,36 & 9,39 & 12,36 \\
\hline NET & 2010 & 62,59 & 47,41 & 49,50 & 58,31 & 16,23 & 8,49 & 9,96 & 13,72 \\
\hline & 2025 & 64,31 & 48,72 & 50,86 & 59,91 & 17,43 & 9,12 & 10,70 & 14,74 \\
\hline & 1996 & 57,06 & 31,13 & 44,88 & 51,58 & 14,19 & 2,04 & 7,41 & 10,69 \\
\hline POR & 2010 & 59,76 & 32,22 & 46,80 & 54,00 & 15,25 & 2,27 & 8,24 & 11,74 \\
\hline & 2025 & 61,97 & 33,41 & 48,54 & 56,00 & 16,55 & 2,46 & 8,94 & 12,74 \\
\hline & 1996 & 60,03 & 43,62 & 52,74 & & 14,85 & 9,59 & 11,49 & \\
\hline UK & 2010 & 62,59 & 45,24 & 54,61 & & 16,26 & 10,02 & 12,23 & \\
\hline & 2025 & 64,45 & 46,58 & 56,23 & & 17,54 & 10,82 & 13,20 & \\
\hline
\end{tabular}

Source: Own computations 
5.6. Education: The key to better future health status of population

The previous exercise of building HE scenarios based on rather crude hypotheses, avoided the shortcomings that using observed trends would have otherwise caused. But even if limiting the extent of our ignorance on this matter it is still unsatisfactory. In order to exploit further the information contained in the ECHP to advance in this direction, we recall the analysis previously made on education and health as a very convenient way to establish some estimates about the composition effects of a more educated population on future health status of EU members' populations

As better educated younger generations replace older generations with lower levels of education, health status of the population would improve in the future. The magnitude of the improvement will depend on the differences in education levels between generations and the differences in health status by education levels.

Given that most people's education levels do not change after age 30, we can project the educational composition of the future population for those who are currently 30 years or older. Assuming that the mortality rate is the same regardless of education level, the educational composition of the population in age $\mathrm{X}$ ten years from now will be the same as that of the population in age X-10 now. Multiplying the health status by age and education with the age-education distribution of the future population, we obtain the projection of health status of future population. We examine the future health status of three age groups, 55-64, 65-74 and 75-84. Assuming that the age-education specific health status remains at the level observed in ECHP 1994, we examine the health status of the three age groups in 2004 and 2014.

As seen on Table 5.8, the potential health improvement due to educational composition is most among the 55-64 age group and least among the 75-84 age group irrespective of the country considered. There are also substantial variations between countries. With respect to the proportion in good health, among the population aged 55-64 it increases by 8 and 9 percentage points in Spain and Greece during the period 1994-2014 while it increases by only one percentage points in Belgium and the Netherlands. For the age group 65-74, the improvement is most (5 percentage points) in Denmark while it is least (1 percentage point) in Portugal. Among those aged 75-84, the improvement is relative small. 


\begin{tabular}{|l|c|c|c|c|c|c|c|c|c|}
\hline \multicolumn{10}{|c|}{ Table5.8 } \\
Proportion in Good Health in 1994 & (observed), 2004 and 2014 (projected) in the EU \\
\hline & \multicolumn{3}{|c|}{ Ages 55-64 } & \multicolumn{3}{c|}{ Ages 65-75 } & \multicolumn{3}{c|}{ Ages 75-84 } \\
\cline { 2 - 11 } & 1994 & 2004 & 2014 & 1994 & 2004 & 2014 & 1994 & 2004 & 2014 \\
\hline Denmark & 0,648 & 0,683 & 0,698 & 0,549 & 0,572 & 0,599 & 0,455 & 0,472 & 0,490 \\
\hline $\begin{array}{l}\text { Netherland } \\
\text { s }\end{array}$ & 0,607 & 0,623 & 0,633 & 0,501 & 0,515 & 0,524 & 0,444 & 0,454 & 0,463 \\
\hline Belgium & 0,598 & 0,624 & 0,634 & 0,486 & 0,497 & 0,526 & 0,374 & 0,378 & 0,389 \\
\hline France & 0,479 & 0,517 & 0,529 & 0,374 & 0,386 & 0,415 & 0,257 & 0,264 & 0,278 \\
\hline UK & 0,617 & 0,642 & 0,659 & 0,506 & 0,520 & 0,540 & 0,435 & 0,442 & 0,457 \\
\hline Ireland & 0,701 & 0,713 & 0,728 & 0,562 & 0,591 & 0,607 & 0,430 & 0,436 & 0,458 \\
\hline Italy & 0,387 & 0,405 & 0,430 & 0,268 & 0,272 & 0,293 & 0,210 & 0,211 & 0,213 \\
\hline Greece & 0,542 & 0,583 & 0,633 & 0,364 & 0,372 & 0,400 & 0,208 & 0,211 & 0,219 \\
\hline Spain & 0,385 & 0,410 & 0,464 & 0,301 & 0,308 & 0,328 & 0,215 & 0,220 & 0,224 \\
\hline Portugal & 0,298 & 0,310 & 0,326 & 0,165 & 0,166 & 0,174 & 0,125 & 0,130 & 0,131 \\
\hline Source: EUROSTAT-ECHP and own computations \\
\hline
\end{tabular}

Similar cross-country differences can be observed in the proportion with disability; Spain and Greece improve most among the population group 55-64, Belgium and France for the 65-75 age group, and Denmark for the oldest age group as shown in Table 5.9.

\begin{tabular}{|l|c|c|c|c|c|c|c|c|c|}
\hline \multicolumn{10}{|c|}{ Table5.9 } \\
Proportion with Disability in 1994 (observed), 2004 and 2014 (projected) in the EU \\
\hline & \multicolumn{3}{|c|}{ Ages 55-64 } & \multicolumn{3}{c|}{ Ages 65-75 } & \multicolumn{3}{c|}{ Ages 75-84 } \\
\cline { 2 - 11 } & 1994 & 2004 & 2014 & 1994 & 2004 & 2014 & 1994 & 2004 & 2014 \\
\hline Denmark & 0,315 & 0,285 & 0,271 & 0,377 & 0,366 & 0,354 & 0,460 & 0,437 & 0,425 \\
\hline $\begin{array}{l}\text { Netherland } \\
\text { s }\end{array}$ & 0,373 & 0,363 & 0,356 & 0,440 & 0,432 & 0,426 & 0,519 & 0,511 & 0,503 \\
\hline Belgium & 0,344 & 0,335 & 0,329 & 0,421 & 0,414 & 0,396 & 0,614 & 0,614 & 0,612 \\
\hline France & 0,281 & 0,255 & 0,249 & 0,389 & 0,378 & 0,350 & 0,537 & 0,534 & 0,528 \\
\hline UK & 0,335 & 0,325 & 0,318 & 0,449 & 0,444 & 0,438 & 0,520 & 0,518 & 0,512 \\
\hline Ireland & 0,260 & 0,248 & 0,231 & 0,392 & 0,383 & 0,376 & 0,493 & 0,490 & 0,478 \\
\hline Italy & 0,322 & 0,304 & 0,280 & 0,444 & 0,441 & 0,427 & 0,580 & 0,584 & 0,581 \\
\hline Greece & 0,289 & 0,266 & 0,238 & 0,375 & 0,368 & 0,350 & 0,532 & 0,533 & 0,526 \\
\hline Spain & 0,366 & 0,350 & 0,315 & 0,403 & 0,398 & 0,383 & 0,557 & 0,554 & 0,552 \\
\hline Portugal & 0,423 & 0,413 & 0,401 & 0,489 & 0,488 & 0,478 & 0,563 & 0,561 & 0,561 \\
\hline Source: EUROSTAT-ECHP and own computations \\
\hline
\end{tabular}

These results clearly point out to a general improvement of the proportion of life years lived in either good health or free of disability beyond the doubts that emerged when we tried to extend observed trends so far. Although we have not tried to estimate figures for $\mathrm{HE}$ based on this approach we believe this is a sound way to overcome the limitations of the simple procedures attempted before. Moreover, the results just commented are compatible with the scenarios also discussed previously. 


\section{Living longer, working less, keeping better? Towards a new demographic transition}

On the basis of the comparison of the different data sets we have concluded that ageing is a process that all countries have been experiencing, with different degrees and starting points, since the last few decades and that will continue, given current trends, in the coming decades.

Ageing is due both to longer average life years and fewer births. Life expectancy has been increasing dramatically since one hundred years ago, and this has been compatible both with expansion (people reaching higher extreme ages) and with compression (more and more people surviving at all ages) of mortality. However, in the last three decades, compression of mortality at adult ages has been dominant in the process of ageing rather than expansion for the generality of countries. Expansion on the other hand, means a higher limit for the human life what, if strictly defined, is not the case being observed. Relatively few people reach extreme ages that only with numbered exceptions surpass 110 years of age while survivors shares (for a given generation) at 80 , for instance, have typically increased from $30 \%$ to $60 \%$ or more in the last 30 years.

Life courses indicators have allowed us to document, with varying accuracy due to data availability for different countries, a general trend in the EU towards longer years in school, delayed entrance to the labour market, delayed emancipation from parental home, delayed household formation and first parenthood, earlier retirement and longer post retirement spans. Some of these trends, as it is well known, clash with each other as it is the case of shorter working lives and longer post retirement spans.

Morbidity (health status or disability) puts a check on the quality with which longer lives can be lived. Data on these issues have not been yet comprehensively analysed due to the rarity and lack of homogeneity of health and disability surveys in different countries. Nevertheless, the European Panel has allowed us to document health and disability status in EU countries and to use this information to compute Adjusted Life Expectancies either for years lived in good health or free of disability. Although some indications for some countries point to the fact that longer lives do not necessarily mean to be lived in better health or with less prevalence of disabilities, when the recent past is analysed with the ECHP data, in general, we can establish scenarios that quite naturally imply increased 
portions of increased post-retirement or adult lives lived either in better health or free of disability. Health and disability status however is self-reported and this makes data fraught with problems and hard to compare among countries. We have shown this using the ECHP data what points to the need of being extremely careful as for making country comparisons on this matter. The close link we have established among education and health status has allowed us nevertheless to support our naïve scenarios for generally improved future health Expectancies.

All in all, European countries have had since the mid past century what could be termed, following van de Kaa (1987), a "second demographic transition" concerning the evolution of fertility and mortality. It is not easy to say whether the absolute limit to a human life has increased, but what is more than certain is that survival at high or even extreme ages has experienced a dramatic change in the last decades in Europe. Not less have changed life styles and behaviours, if we trust our "lifecourses" indicators that warn us about possible unsustainable combinations of trends that will have to be contained before society discover too late that liabilities are much higher than assets of any kind. Activity seems to be the most abundant and most wasted resource in western countries whereas health and disability problems seem to be checked as post retirement life spans increase, although not everywhere.

Ageing will continue in the future even at an accelerated speed, at least when defined in the rather strict manner we still define it (65s and over). Health and disability limitations would probably advance less rapidly than age thus allowing for healthier life, but this is not granted necessarily as analyses based on available data still lack conclusiveness. Despite the enormous advancement in health in developed countries, ageing critically exposes people to new forms of morbidity. Perhaps some future day we could speak of a "third demographic transition" in Europe (and everywhere). That of a more balanced equilibrium between age spans within the life cycle, healthier lifestyles, more active and less dependent old age lives or improved options as for the transition from work to retirement. 


\section{References}

Ahn, Namkee (2002), “Assessing self-assessed health data”, Working Paper No. 2002-24, FEDEA, available at ftp://ftp.fedea.es/pub/Papers/2002/dt2002-24.pdf

Bound, J (1991) "Self-reported versus objective measures of health in retirement models", Journal of Human Resources, 26: 106-38.

Dwyer, DS and OS Mitchell (1999) "Health problems as determinants of retirement: Are self-rated measures endogenous?", Journal of Health Economics 18(2): 173-193.

Elo, IT and SH Preston (1996) "Educational differentials in mortality: United States, 19791985”, Social Science and Medicine 42(1): 47-57.

Freedman, VA and LG Martin (1999) "The role of education in explaining and forecasting trends in functional limitations among older Americans”, Demography 36(4): 461473.

Mathers, C. and J. M. Robine, 1993, "Health expectancy indicators: a review of the work of REVES to date", in J. M. Robine, C. Mathers, M. Bone and I. Romieu (Eds.) Calculation of health expectancies: harmonisation, consensus achieved and future perspectives. London, John Libbey, 1993.

Mathers, C. D., 2003, "Introduction, Part IV: Health Expectancies in the Different Regions of the World". In Robine JM, Jagger C, Mathers CD, Crimmins EM, Suzman RM. Determining Health Expectancies, London, John Wiley.

Robine, Jean-Marie, Carol Jagger and Isabelle Romieu, 2001, "Disability-free life expectancies in the European Union countries: calculation and comparisons", Genus, LVII(n. 2), 89-101.

Robine, Jean-Marie, Isabelle Romieu and Emmanuelle Cambois, 1999, "Health expectancy indicators", WHO Bulletin, 1999, 77(2): 181-185.

Sadana R, Mathers CD, Lopez A, Murray CJL, Iburg KM (2002) "Comparative Analyses of more than 50 household surveys on health status", in Murray CJL, Salomon JA, Mathers CD, Lopez AD (2002) Summary Measures of Population Health. Concepts, Ethics, Measurement and Applications, Geneva, World Health Organization.

Smith, JP (1999) "Healthy bodies and thick wallets: the dual relation between health and economic status", Journal of Economic Perspectives 13(2): 145-166.

Sullivan, D.F., 1971, "A single index of mortality and morbidity". HSMHA Health Reports, 1971, 86:347-354.

Van de Kaa, Dirk J. (1987), “Europe's Second Demographic Transition”, Population Bulletin, vol. 42(1).Population Reference Bureau, March 1987.

WHO, 2000, Health Systems: improving performance. World Health Report 2000, Geneva, 2000.

WHO, 2001, Mental Health: new understanding, new hope. World Health Report 2001, Geneva, 2001. 
WHO, 2002, Reducing Risks, Promoting Healthy Life. World Health Report 2002, Geneva, 2002. 


\section{CESifo Working Paper Series}

(for full list see www.cesifo.de)

963 Jakob de Haan, Jan-Egbert Sturm and Bjørn Volkerink, How to Measure the Tax Burden on Labour at the Macro-Level?, June 2003

964 Harry Grubert, The Tax Burden on Cross-Border Investment: Company Strategies and Country Responses, June 2003

965 Kirk A. Collins and James B. Davies, Measuring Effective Tax Rates on Human Capital: Methodology and an Application to Canada, June 2003

966 W. Steven Clark, Using Micro-Data to Assess Average Tax Rates, June 2003

967 Christopher Heady, The 'Taxing Wages' Approach to Measuring the Tax Burden on Labour, June 2003

968 Michael P. Devereux and Alexander Klemm, Measuring Taxes on Income from Capital: Evidence from the UK, June 2003

969 Bernhard Eckwert and Itzhak Zilcha, The Effect of Better Information on Income Inequality, June 2003

970 Hartmut Egger and Josef Falkinger, The Role of Public Infrastructure for Firm Location and International Outsourcing, June 2003

971 Dag Morten Dalen and Trond E. Olsen, Regulatory Competition and Multi-national Banking, June 2003

972 Matthias Wrede, Tax Deductibility of Commuting Expenses and Residential Land Use with more than one Center, June 2003

973 Alessandro Cigno and Annalisa Luporini, Scholarships or Student Loans? Subsidizing Higher Education in the Presence of Moral Hazard, June 2003

974 Chang Woon Nam, Andrea Gebauer and Rüdiger Parsche, Is the Completion of EU Single Market Hindered by VAT Evasion?, June 2003

975 Michael Braulke and Giacomo Corneo, Capital Taxation May Survive in Open Economies, July 2003

976 Assar Lindbeck, An Essay on Welfare State Dynamics, July 2003

977 Henrik Jordahl and Luca Micheletto, Optimal Utilitarian Taxation and Horizontal Equity, July 2003 
978 Martin D. D. Evans and Richard K. Lyons, Are Different-Currency Assets Imperfect Substitutes?, July 2003

979 Thorsten Bayindir-Upmann and Frank Stähler, Market Entry Regulation and International Competition, July 2003

980 Vivek Ghosal, Firm and Establishment Volatility: The Role of Sunk Costs, Profit Uncertainty and Technological Change, July 2003

981 Christopher A. Pissarides, Unemployment in Britain: A European Success Story, July 2003

982 Wolfgang Buchholz, Richard Cornes, and Wolfgang Peters, On the Frequency of Interior Cournot-Nash Equilibria in a Public Good Economy, July 2003

983 Syed M. Ahsan and Panagiotis Tsigaris, Choice of Tax Base Revisited: Cash Flow vs. Prepayment Approaches to Consumption Taxation, July 2003

984 Campbell Leith and Jim Malley, A Sectoral Analysis of Price-Setting Behavior in US Manufacturing Industries, July 2003

985 Hyun Park and Apostolis Philippopoulos, Choosing Club Membership under Tax Competition and Free Riding, July 2003

986 Federico Etro, Globalization and Political Geography, July 2003

987 Dan Ariely, Axel Ockenfels and Alvin E. Roth, An Experimental Analysis of Ending Rules in Internet Auctions, July 2003

988 Paola Conconi and Carlo Perroni, Self-Enforcing International Agreements and Domestic Policy Credibility, July 2003

989 Charles B. Blankart and Christian Kirchner, The Deadlock of the EU Budget: An Economic Analysis of Ways In and Ways Out, July 2003

990 M. Hasham Pesaran and Allan Timmermann, Small Sample Properties of Forecasts from Autoregressive Models under Structural Breaks, July 2003

991 Hyun Park, Apostolis Philippopoulos and Vangelis Vassilatos, On the Optimal Size of Public Sector under Rent-Seeking competition from State Coffers, July 2003

992 Axel Ockenfels and Alvin E. Roth, Late and Multiple Bidding in Second Price Internet Auctions: Theory and Evidence Concerning Different Rules for Ending an Auction, July 2003

993 Pierre Salmon, The Assignment of Powers in an Open-ended European Union, July 2003

994 Louis N. Christofides and Chen Peng, Contract Duration and Indexation in a Period of Real and Nominal Uncertainty, July 2003 
995 M. Hashem Pesaran, Til Schuermann, Björn-Jakob Treutler, and Scott M. Weiner, Macroeconomic Dynamics and Credit Risk: A Global Perspective, July 2003

996 Massimo Bordignon and Sandro Brusco, On Enhanced Cooperation, July 2003

997 David F. Bradford, Addressing the Transfer-Pricing Problem in an Origin-Basis X Tax, July 2003

998 Daniel Gros, Who Needs Foreign Banks?, July 2003

999 Wolfram Merzyn and Heinrich W. Ursprung, Voter Support for Privatizing Education: Evidence on Self-Interest and Ideology, July 2003

1000 Jo Thori Lind, Fractionalization and the Size of Government, July 2003

1001 Daniel Friedman and Donald Wittman, Litigation with Symmetric Bargaining and TwoSided Incomplete Information, July 2003

1002 Matthew Clarke and Sardar M. N. Islam, Health Adjusted GDP (HAGDP) Measures of the Relationship Between Economic Growth, Health Outcomes and Social Welfare, July 2003

1003 Volker Grossmann, Contest for Attention in a Quality-Ladder Model of Endogenous Growth, August 2003

1004 Marcel Gérard and Joan Martens Weiner, Cross-Border Loss Offset and Formulary Apportionment: How do they affect multijurisdictional firm investment spending and interjurisdictional tax competition?, August 2003

1005 Burkhard Heer, Nonsuperneutrality of Money in the Sidrauski Model with Heterogeous Agents, August 2003

1006 V. Anton Muscatelli, Piergiovanna Natale, and Patrizio Tirelli, A Simple and Flexible Alternative to the Stability and Growth Pact Deficit Ceilings. Is it at hand?, August 2003

1007 Reto Foellmi and Josef Zweimüller, Inequality and Economic Growth: European Versus U.S. Experiences, August 2003

1008 James S. Costain and Michael Reiter, Business Cycles, Unemployment Insurance, and the Calibration of Matching Models, August 2003

1009 Marco Runkel, Optimal Contest Design when the Designer's Payoff Depends on Competitive Balance, August 2003

1010 Donald O. Parsons, Torben Tranaes and Helene Bie Lilleør, Voluntary Public Unemployment Insurance, August 2003

1011 Rüdiger Pethig and Andreas Wagener, Profit Tax Competition and Formula Apportionment, August 2003 
1012 Johan Willner, Privatisation and Public Ownership in Finland, August 2003

1013 Seppo Kari and Jouko Ylä-Liedenpohja, Taxation and Valuation of International Real Investments, August 2003

1014 James Heckman, Rosa Matzkin and Lars Nesheim, Simulation and Estimation of Hedonic Models, August 2003

1015 Biswa N. Bhattacharyay, Towards a Macro-Prudential Leading Indicators Framework for Monitoring Financial Vulnerability, August 2003

1016 J. Stephen Ferris and Stanley L. Winer, Searching for Keynes: With Application to Canada, 1870-2000, August 2003

1017 Massimo Bordignon, Luca Colombo and Umberto Galmarini, Fiscal Federalism and Endogenous Lobbies' Formation, August 2003

1018 Annette Alstadsæter, The Dual Income Tax and Firms'Income Shifting through the Choice of Organizational Form and Real Capital Investments, August 2003

1019 Peter Fredriksson and Bertil Holmlund, Optimal Unemployment Insurance Design: Time Limits, Monitoring, or Workfare?, August 2003

1020 Kashif S. Mansori, Following in their Footsteps: Comparing Interest Parity Conditions in Central European Economies to the Euro Countries, August 2003

1021 Christoph Borgmann and Matthias Heidler, Demographics and Volatile Social Security Wealth: Political Risks of Benefit Rule Changes in Germany, August 2003

1022 Kjell Erik Lommerud, Bjørn Sandvik and Odd Rune Staume, Good Jobs, Bad Jobs and Redistribution, August 2003

1023 Patrick Karl O'Brien, The Governance of Globalization: The Political Economy of Anglo-American Hegemony, 1793-2003, September 2003

1024 Antonio Ciccone and Giovanni Peri, Skills' Substitutability and Technological Progress: U.S. States 1950-1990, September 2003

1025 Bjørn Sandvik, Optimal Taxation and Normalisations, September 2003

1026 Massimo Bordignon and Gilberto Turati, Bailing Out Expectations and Health Expenditure in Italy, September 2003

1027 José A. Herce, Namkee Ahn, Ricard Génova, and Joaquín Pereira, Bio-Demographic and Health Aspects of Ageing in the EU, September 2003 